\title{
Treatment of Acquired Autoimmune Myasthenia Gravis: a Topic Review
}

\author{
Pradeep Verma and Joël Oger
}

\begin{abstract}
We propose a new approach to staging the disease based on clinical and immunological response to treatment. We oppose clinical remission to immunological remission and define total clinical remission as the goal of therapy. We describe the use, side effects and indications of established therapies. Acetycholine esterase inhibitors are only a symptomatic treatment as is plasma exchange. Usefulness and limits of thymectomy, corticosteroids and immunosuppressants are described here. Their goal is to reduce the auto-immune process. Long-term hazards from these medications are described and methods to reduce their potential risks are suggested. We suggest the number of patients having life threatening complications while undergoing aggressive immunosuppression can be reduced by a systematic approach to follow-up. In the second part of this review article, adapting management to specific situations is emphasized in refractory disease, respiratory failure, neonatal and juvenile forms of the disease. The special situation of seronegative myasthenia is discussed.

RÉSUMÉ: Nous proposons une nouvelle description de l'évolution de la maladie basée sur la clinique et l'immunologie. Nous différençions rémission clinique et rémission immunologique. L'objectif thérapeutique est devenu la rémission clinique totale. Nous décrivons les traitements utilisés, leurs riques potentiels et les indications de leur utilisation. Les inhibitreurs de l'acetylcholine estérase sont un traitement symptomatique comme la plasmaphérèse. L'indication et les risques de la thymectomie, des stéroides et des immunosuppresseurs sont décrits. Les complications iatrogènes sont discutée avec les techniques permettant de les minimiser. Une approche systêmatique du traitement permet de réduire les risques de l'immunosuppression. La deuxième moitié de cette revue est consacrée à l'application de ces principes aux situations représentée par la myasthénie réfractaire au traitement, la détresse respiratoire, les formes néo-natales et juvéniles. La situation très particulière représentée par la myasthénie séronégative est aussi discutée.
\end{abstract}

Can. J. Neurol. Sci. 1992; 19: 360-375

Fluctuating weakness is easily diagnosed as myasthenia gravis (MG) if one maintains a high index of suspicion. Improvement with anticholinesterases strengthens the clinical suspicion at bedside. Repetitive nerve stimulation studies, and single fibre EMG, localize dysfunction to the neuromuscular junction. Finally, presence of serum antibodies against the acetylcholine receptor (AchR Ab) confirms the diagnosis. Such a combined clinical-laboratory diagnosis of MG is highly accurate.

Clinical diagnosis is not always simple and $\mathrm{MG}$ presentation is polymorphic; although it is characterised by its restriction to motor function.' Failure to diagnose $M G$ in the early stages is frequent and this condition is notorious for remaining undiagnosed for a long time. We have managed a woman diagnosed at age 84 , when the first of 6 exacerbations of MG had occurred at age 14. It is customary to stress the need for an early diagnosis because of its bearing on therapy and prognosis, even though this has never been proven. MG:

General agreement exists on four principles in the therapy of

(1) Anticholinesterases are helpful in all forms of $\mathrm{MG}$,
(2) Steroid or cytotoxic immunosuppressive drugs are the mainstay of the immune therapy of MG

(3) Thymectomy is indicated in most cases and mandatory if a thymoma is suspected; and

(4) Plasma exchange, though effective, is practical on a short term basis only.

Over the last decade the treatment of MG has improved dramatically and in most instances total clinical remission with practically normal quality of life can be expected. Therapeutic decision-making in MG still remains difficult as empiricism prevails.

\section{Natural history of MG}

In modern days the natural history of MG is impossible to describe because all patients are treated. Randomized and stratified double blind controlled studies have not been done for any of the therapeutic modalities presently used. Such studies are assumed to be impractical on an ethical basis but we plead for a change in that attitude now that experimental trials represent a well established segment of experimental medicine.

From the Department of Medicine/Neurology, University Hospital and University of British Columbia, Vancouver Received October 1, 1991. Accepted in final form February 14, 1992

Reprint requests to: Joël Oger, D en M, FRCPC, University Hospital UBC site, 2211 Wesbrook Mall, Vancouver, British Columbia, Canada V6T 2B5 
To evaluate the impact of the various therapeutic interventions in MG, one has to rely on the impact of such interventions on mortality statistics in various times. Sources of data are limited to old mortality and morbidity studies. ${ }^{2.3}$ Reduction in mortality has occurred in a step-wise fashion, correlating with advances in therapy of the disease.

In the 1930's, the spontaneous remission rate was reported to be $40 \%$ in ocular MG, and $10-15 \%$ in generalized MG; remissions occurred only after several years. ${ }^{3}$ After 3-4 relapses remissions were usually incomplete. ${ }^{4}$ In the 1940-1960 period, mortality was $30 \%$ and deaths occurred within 3 years of onset, ${ }^{5}$ essentially due to respiratory failure. ${ }^{6.7}$ The remission rate increased three-fold after thymectomy was introduced. ${ }^{8}$ In the 1970's, amongst some controversy, ACTH was used as treatment for MG for a decade, prior to the suggestion by Simpson that MG was an immune disorder. ${ }^{9.10}$ In 1971 oral prednisone became established as a treatment in MG. ${ }^{11.12}$ Spontaneous complete remissions occurred in about $25 \%$ of MG patients but lasted no longer than 2 years. Nearly $90 \%$ of patients with ocular MG became generalized over the next 3-4 years; the overwhelming majority (84\%) within one year. ${ }^{13}$ Patients who survived the initial 5 years of illness had a very low mortality but sometimes had severe residual weakness. ${ }^{14}$

Mortality attributable to MG is now almost nonexistent and remissions seem to be induced earlier. Simpson's observation that mortality statistics have not improved with the introduction of immunosuppressants, such as steroids and Azathioprine, over the last two decades should be viewed in the light of increased survival of MG patients. Simpson insists that there are the few patients who would have died from acute myasthenic crises and now die from complications of immunosuppression but only after several years. We follow Linton and Philcox ${ }^{15}$ in their opinion that most deaths are probably preventable with current knowledge of the disease and modern intensive care capabilities. Simpson stresses that deaths due to Azathioprine (agranulocytosis and hepatitis) are not preventable because they are idiosyncratic reactions. We disagree with this statement as close monitoring of blood cell counts and liver enzymes permits recognition of toxicity early enough to avoid lethal delays.

\section{A new classification of MG and goal of therapy}

Clinical severity based on Osserman's classification ${ }^{16}$ remains useful to describe clinical disease but a modern classification has to take into account need for medications and immune status (acetylcholine receptor antibodies). We propose a comprehensive combined clinical gradation and immunological classification which keeps the clinical gradation of Osserman intact. Complete clinical remission in MG consists of disappearance of all weakness, without any need for anticholinesterases. If oral anticholinesterases are needed to keep patients nearly asymptomatic, this should be called a partial clinical remission. Antibody titres are then evaluated to describe immunological remission and sub-clinical cases (Table 1). Comprehensive modern management should lead to complete or partial remission in most patients and neither $M G$ nor its therapy should be directly responsible for any death.

\section{Pathogenesis}

Human autoimmune MG results from an attack both by antibodies and macrophages directed against acetylcholine receptor
Table 1. Proposing a New Classification for Immune MG

1) Pre-clinical (subclinical) immune disease: antibody positive, no signs and symptoms

2) Clinical disease (see Osserman's classification): Presence of signs and symptoms; no reference to antibody status

Type I Pure ocular myasthenia

Type IA ocular MG with EMG abnormality in limb muscles

Type IIA Mild generalized myasthenia (without bulbar features)

Type IIB Moderately severe generalized myasthenia

(with bulbar features)

Type III Acute severe generalized myasthenia

Type IV Chronic severe generalized myasthenia

3) Incomplete (partial) clinical remission: No signs and symptoms but AchE inhibitors required; no reference to antibody status

4) Complete clinical remission: No signs and symptoms no need for or improvement with AchE inhibitors; still antibody positive

5) Complete clinical and immunologic remission: No signs and symptoms; no need for AchE inhibitors (can use steroids and IS but no recent Plex) antibody positivity has been substantiated and has disappeared.

(AchR). AchR density at the motor end plate (post-synaptic) is reduced and some of the remaining receptors are rendered nonfunctional; this results in failure of neuromuscular transmission on exercise, (reduction of the "safety factor" of the neuromuscular transmission). The trigger(s) of the auto-immune response in MG remains to be discovered. Readers interested in detailed reviews of pathogenesis may consult reviews by Engel, ${ }^{17}$ by Drachman ${ }^{18}$ or by others. ${ }^{19-23}$

Three stages in autoimmune disorders have been suggested by Simpson; ${ }^{24}$ each possibly lasting from a few weeks to a decade. Stage 1 (active) shows multiple clear-cut relapses and remissions. Most of the damage to the end organs appears, mortality is maximal and response to immune therapy is the best. Stage 2 (decline) shows incomplete remissions and mild relapses but with a low mortality and only modest benefit of immune treatment. In stage 3 (burnt out) stable irreversible residual damage to end the organ has established. Immune therapy may achieve nothing in this stage. We suggest that patients with MG be staged both in terms of clinical and immune activity before planning therapy and making prognostic comments.

\section{Pre-treatment evaluation}

Because of the potentially serious and long-lasting nature of both illness and treatment, the following steps are recommended before initiating treatment in MG. 1) Confirmation of the diagnosis by electrophysiological and immunological testing. 2) Assessment of weakness by detailed clinical testing useful for further comparison and possibly suggesting spontaneous remission. ${ }^{13} 3$ ) Evaluation of contra-indications (especially asthma, diabetes and tuberculosis) and pathogenetically related diseases like lupus, rheumatoid arthritis and thyroid disease, etc., which show an increased incidence in patients with MG. 4) Lung function testing has a special place in the assessment of MG as respiratory failure is how this disease kills. Clinical assessment is less reliable than measurement of respiratory muscle function. Patients with otherwise mild MG may be found to have substantial respiratory weakness. Respiratory failure can develop insidiously while limb muscle strength is stable; patients do not appear outwardly to be in respiratory distress as their distress can be masked by weakness of facial expression. 5) Referral to local self-help groups such as local chapters of the MG 
Foundation is helpful in educating patients and families about MG and providing social and moral support.

\section{Treatments Avallable}

\section{a) Anticholinesterase agents}

These drugs enhance neuromuscular transmission by inhibiting the activity of cholinesterases (ChE) which hydrolyse intrasynaptic acetylcholine (Ach). Suppression of hydrolysis of Ach increases the amount of this transmitter in the synaptic cleft of the neuromuscular junction (NMJ), leading to prolongation of the action of Ach on the muscle endplate with partial and temporary correction of the defect in the "safety factor". Because of good efficacy and negligible long-term toxicity, these drugs remain the cornerstone of symptom control in MG. However, continuous individualized titration of dose is required, because requirements vary from day to day, and as the disease remits or relapses. The timing of anticholinesterase medication must be coordinated with periods of important activities like meals or work.

Anticholinesterase drugs are nearly always effective in most forms of MG and constitute the mainstay of drug therapy in ocular MG. ${ }^{25}$ No placebo-controlled trial has ever been done with these drugs, as their effects are so prompt, spectacular and convincing. Each of the anticholinesterases, pyridostigmine and neostigmine, can be used alone or in combination. Pyridostigmine is more popular, perhaps because of presumed lower incidence of muscarinic side-effects. Only a few patients benefit so much from the anticholinesterase drugs that additional therapies can be avoided. Both under-treatment and over-treatment may result in life-threatening pharyngeal and respiratory weakness. Despite their good diagnostic utility and dramatic initial therapeutic success, these drugs have four common limitations:

1) Muscarinic effect. Abdominal cramping and secretory diarrhea result from excess cholinergic stimulation in smooth muscle and exocrine glands. It is important to control diarrhea to insure adequate absorption of other medications (Azathioprine). Loperamide (Imodium ${ }^{\circledR}$ ) with anticholinergic effects restricted to the G.I. tract can be used without interfering with neuromuscular transmission.

2) Incomplete restoration of decrement in power. In fact Enge ${ }^{17}$ states "Because of their side effects, anticholinesterase drugs are used to decrease rather than to eliminate the symptoms of MG" and "cholinergic and myasthenic failure of transmission can exist simultaneously in different muscles, or even in different fibres of the same muscles". We agree with the implication of these statements that complete relief is not to be expected. Interestingly, patients with mild neuromuscular disease adapt to the subnormal power so well that they feel and test 'normal'. Some patients who seem adequately treated by anticholinesterases alone, probably need further optimization of therapy and adding other agents or increasing the dose can improve their quality of life.

3) Poor efficacy in restricted forms of MG. In some patients with pharyngeal weakness, if anticholinesterase dosage is increased to clear pharyngeal symptoms completely, deterioration in respiratory muscle function can be observed.

4) Loss of efficacy after a few years of use. Indeed, in some patients a refractory and irreversible motor deficit seems to set in with time. Little is known about the pathogenesis and effective management of this state but chronic use of these agents has been suggested to contribute to this irreversible state probably by reducing the number of receptors at the NMJ. ${ }^{26.27}$ Experimental evidence shows that only very high doses of anticholinesterase drugs (used in animals) can produce morphological changes at the neuromuscular junction.

Anticholinesterase dose reduction must be sought constantly to minimize side effects. The minimum dose required for maximal symptom relief can also provide an estimate of disease severity, which in turn guides one in recommending immunosuppressive therapy.

Very low bioavailability (10-20\%) of anticholinesterases ${ }^{28}$ and variations in bioavailability make the therapeutic dose and toxic dose vary widely, even for the same patient. ${ }^{29.30}$ Poor and erratic absorption explains the very high oral/parenteral dose ratios of these drugs. ${ }^{31} \mathrm{~A}$ reduction in absorption may be produced by diarrhea, antacids or a high fibre diet. As absorption varies substantially, clinically relevant overdosing can similarly occur without any change in the amount of drug ingested. Plasma levels of drugs are not useful for clinical monitoring as the effect at the NMJ receptor is more determined by receptor affinity and competitive block by antibodies than by drug levels.

Cholinergic crisis is uncommon with modern anticholinesterase dosage. It must be suspected in all cases of obscure respiratory failure. Muscarinic signs (miosis, sialorrhea, bronchorrhea, diarrhea) and nicotinic signs (cramps and fasciculations) suggest cholinergic excess. In the 1940's and 1950's, when up to $15000 \mathrm{mg}$ of neostigmine were used, some deaths likely resulted from anticholinesterase over-dosage. Between 1960 and 1980, the rate of crisis remained steady at $12-16 \%$, although the fatality rate from crisis dropped from $42 \%$ to $6 \%$ and the overall mortality dropped from $12 \%$ to $3.3 \% .{ }^{32}$ At present, cholinergic crises are observed only in patients who aim at obtaining complete resolution of symptoms and who progressively increase their medication. Patients with greatly reduced receptor density would be more vulnerable to cholinergic crisis. The dose at which a given MG patient will experience weakness from cholinergic excess is variable and unpredictable.

Once cholinergic crisis is suspected, anticholinesterases are withheld. Diagnosis is confirmed by the improvement on withholding anticholinesterase for several hours. If doubt persists, an Edrophonium test is indicated. Indications for intubation and mechanical ventilation in cholinergic crisis are similar to that of myasthenic crisis (see further).

Edrophonium (Tensilon $\circledast$ ) test The pharmacodynamics of this anticholinesterase agent are so rapid, dramatic and transient that it can be readily used as a diagnostic agent for detecting post-synaptic disorders of neurotransmission. For bedside diagnosis, it is critical to test an objectively weak muscle. The test dose of edrophonium is $10 \mathrm{mg}$ but only $2 \mathrm{mg}$ IV is given initially to check for possible excessive muscarinic effects which can produce severe bradycardia, hypotension and occasionally ventricular fibrillation. A prefilled syringe of atropine sulfate $(1 \mathrm{mg})$ should be at hand prior to administration of the pre-test dose. The rest of the edrophonium $(8 \mathrm{mg})$ must be given rapidly. False positivity has been reported with ALS, ${ }^{33}$ brainstem gliomas ${ }^{34}$ and polymyositis. ${ }^{35}$ The optimal temperature for $\mathrm{ChE}$ activity is $37^{\circ} \mathrm{C}$ and its activity is inhibited by lowering the 
temperature. Cooling the eye lids can result in a dramatic but short lasting improvement of ptosis and forms the basis for the 'ice pack test', an equivalent of the edrophonium test.

Because several anticholinesterases are commercially available which differ only in their pharmacokinetics, familiarity with three is suggested: - an ultrashort-acting (edrophonium or Tensilon $($ )), a short-acting (neostigmine or Prostigmine $($ ) and a long-acting (pyridostigmine or Mestinon ${ }^{\circledR}$ ). Ambenonium or Mytelase ${ }^{\circledR}$ is used only rarely. The usefulness of very long-acting anticholinesterase like phospholine iodide is unclear. Pyridostigmine bromide (Mestinon $\left({ }^{B}\right)$ is the anticholinesterase agent of choice. Usually patients are started with $60 \mathrm{mg}$ of pyridostigmine 4 times daily for a few days and then the dose is adjusted to obtain the maximum efficacy with acceptable side effects. Slow-release tablets (Mestinon ${ }^{\circledR}$ supraspan $180 \mathrm{mg}$ ) are available. Pyridostigmine has been claimed to be more effective in ameliorating pharyngeal weakness than neostigmine with less prominent muscarinic side effects. ${ }^{36.37}$ Table 2 lists equivalent dosages, dosing intervals and relative potencies to facilitate safe substitution of one agent for the other. It is noteworthy that the bromide ion of Mestinon ${ }^{\circledR}$ (pyridostigmine bromide) will be recorded in the electrolyte measurement as chloride $\left(\mathrm{Cl}^{-}\right)$and thus produce an apparent reduction of ion gap with underestimation of bicarbonates.

Several observations of clinical relevance have been made regarding anticholinesterases. 1) The anticholinesterase requirement is greater during disease activity and decreases during remissions. 2) Patients differ in their responsiveness to anticholinesterases presumably due to differences in the amounts of acetylcholine blocking antibodies. 3) The anticholinesterase requirement decreases rapidly following plasmapheresis and thymectomy, requiring reduction of dose after surgery.

\section{Pharmacological interactions with anticholinesterases}

Drugs, toxins and ions which are relatively or absolutely contraindicted in MG are listed in Table 3 (after Argov and Mastaglia). ${ }^{38}$ The hypersecretory state induced by anticholinesterases may increase the risk of GI hemorrhage by steroids. Muscarinic side effects can be minimized by the potent anti-muscarinic effects of $0.5-1.0 \mathrm{mg}$ atropine every 3-4 hours. It may be falsely reassuring to mask muscarinic side effects as they provide the sole method for monitoring toxicity. The nicotinic component of toxicity is more subtle but is the life threatening one.

\section{b) Adrenal corticosteroids}

Steroids suppress IgG secretion rather weakly. ${ }^{39}$ Steroids have been reported to reduce antibody titres more than other immunosuppressants. ${ }^{40}$ They also produce lysis of cortical thymocytes and sequestration of circulating $T$ lymphocytes in the bone marrow, resulting in lymphocytopenia. They inhibit lymphocyte activation by reducing the production of lymphokines (like IL-2) and expression of IL2 receptors. Steroids also inhibit recruitment of cells into the inflammatory site.

Although there is an overwhelming consensus on the efficacy of steroids in $\mathrm{MG}$, the data are largely uncontrolled and observations unblinded, except for a preliminary report on minimally affected patients. ${ }^{41}$ Forty to $80 \%$ of patients undergo a complete and $20-40 \%$ a partial remission when treated with oral prednisone. ${ }^{42}$ In one study, the average latency for significant improvement was 4.9 months and the average dosage was $68 \mathrm{mg}$ on alternate days. ${ }^{13}$ In most patients an initial deterioration in the intensity and extent of weakness is observed when treatment is initiated in high doses. The short-lived increase in weakness at the initiation of steroid therapy appears after 48-96

Table 2. Anticholinestrase Drugs Used in MG

\begin{tabular}{|c|c|c|c|c|c|}
\hline Name of Drug & $\begin{array}{l}\text { Usual } \\
\text { Dose (route) }\end{array}$ & $\begin{array}{c}\text { Dispensed } \\
\text { as } \\
\text { (mg) }\end{array}$ & $\begin{array}{c}\text { Effect } \\
\text { onset } \\
\text { (minutes) }\end{array}$ & $\begin{array}{c}\text { Effect } \\
\text { duration } \\
\text { (minutes) }\end{array}$ & Major indication \\
\hline $\begin{array}{l}\text { Edrophonium } \\
\text { (Tensilon) }\end{array}$ & $5-10($ IV $)$ & $\begin{array}{c}10 \mathrm{mg} \\
(\operatorname{Inj})\end{array}$ & $1-2$ & $<5$ & $\begin{array}{l}\text { Diagnosis of MG and assessment } \\
\text { of adequacy of therapy and toxicity }\end{array}$ \\
\hline $\begin{array}{l}\text { Neostigmine } \\
\text { (Prostigmine) }\end{array}$ & $\begin{array}{l}15-30(\mathrm{PO}) \\
7.5-45 \mathrm{mg} \mathrm{q} 2-6 \mathrm{~h}\end{array}$ & $\begin{array}{l}15 \mathrm{mg} \\
(\mathrm{tab})\end{array}$ & 15 & 120 & $\begin{array}{l}\text { For short term help with } \\
\text { certain special vital activities }\end{array}$ \\
\hline $\begin{array}{l}\text { Neostigmine } \\
\text { methylsulfate }\end{array}$ & $\begin{array}{l}1 \mathrm{mg} / \mathrm{ml} \\
(\mathrm{IM} / \mathrm{SC})\end{array}$ & $\begin{array}{l}0.25,0.5 \\
1.0-2.0\end{array}$ & $\begin{array}{l}2-3 \\
(\operatorname{lnj})\end{array}$ & $\begin{array}{l}10-15 \\
\text { Inj }\end{array}$ & $\begin{array}{l}\text { Diagnosis of MG and assessment } \\
\text { of adequacy of therapy }\end{array}$ \\
\hline $\begin{array}{l}\text { Pyridostigmine } \\
\text { (Mestinon) }\end{array}$ & $60-240(\mathrm{PO})$ & $\begin{array}{l}60 \mathrm{mg} \\
(\mathrm{tab})\end{array}$ & 30 & $200-400$ & $\begin{array}{l}\text { Regular symptomatic therapy } \\
\text { Given every 3-6 hours }\end{array}$ \\
\hline $\begin{array}{l}\text { Pyridostigmine } \\
\text { (Mestinon) }\end{array}$ & $60-240(\mathrm{PO})$ & $\begin{array}{l}12 \mathrm{mg} / \mathrm{ml} \\
\text { (syrup) }\end{array}$ & 30 & $200-400$ & For children and tube-fed patients \\
\hline $\begin{array}{l}\text { Pyridostigmine } \\
\text { (Mestinon supraspan) }\end{array}$ & $90-180(\mathrm{PO})$ & $\begin{array}{l}180 \mathrm{mg} \\
(\mathrm{tab})\end{array}$ & 30 & $? 400-600$ & $\begin{array}{l}\text { Given at bed time only } \\
\text { as supplemental symptomatic therapy }\end{array}$ \\
\hline Pyridostigmine* & $1-5(\mathrm{IM} / \mathrm{SC})$ & $\underset{\text { (Inj) }}{5 \mathrm{mg} / \mathrm{ml}}$ & 5 & $\begin{array}{l}30-120 \\
\text { Inj }\end{array}$ & \\
\hline $\begin{array}{l}\text { Ambenonium* } \\
\text { (Myetelase) }\end{array}$ & $5-25(\mathrm{PO})$ & $\underset{\text { (tab) }}{10 \& 25 \mathrm{mg}}$ & & $250-400$ & Given every 3-6 hours \\
\hline Distigmine* & $5-20(\mathrm{PO})$ & $5 \mathrm{mg}$ & $\begin{array}{r}540 \\
(\operatorname{tab})\end{array}$ & 24 hours & $\begin{array}{l}\text { Once daily dosage } 30 \mathrm{~min} \text { before } \\
\text { breakfast for poorly compliant }\end{array}$ \\
\hline
\end{tabular}

Slow release and liquid forms of neostimine and pyridostigmine are available.

* Not available in Canada. (Adapted from Finley JC and Pascuzzi RM Rational therapy of MG. Seminars in Neurology 1990; 10: 70-82). 
hours and lasts from 1 to 14 days. It may be due to a direct neuromuscular blocking effect of the steroids. We suspect steroids can also produce an initial rise in the antibody titres from lympholysis. This can be avoided by progressively increasing the dosage by $10-20 \mathrm{mg}$ in weekly steps. Alternatively, high doses can be combined with plasma exchange to avoid reduced function. Long-term steroid therapy is often limited by side effects. In a study of 151 patients, these were seen in $66 \%$ patients $s^{43.44}$ of which $27 \%$ were serious (gastrointestinal hemorrhages, aseptic necrosis of femoral head and vertebral fractures)..$^{45}$ Patients on long-term prednisone should be on a low-salt and low calorie-high-protein diet, and take supplemental potassium, calcium and if appropriate, estrogens. They must be cautioned against abruptly stopping steroids because of the risk of worsening MG and precipitating adrenal crisis. Although, long-term effects of steroids are likely to be immunological, short term effects of steroids at the NMJ are most likely pharmacological.$^{46}$ Steroids partially antagonize the blocking effects of hemicholinium-3 (HC-3) in vitro ${ }^{47}$ and in vivo. ${ }^{48}$

Presently steroids are used in about two-thirds of MG patients at some stage in their illness. Clinical improvement following prednisone is often accompanied by a decrease in antibody titre. The latency for reduction of the antibody titre varies, but the most striking drops usually appear within 3 months of initiation of therapy. Like Engel et al., ${ }^{49}$ we suggest initiating with large doses (100 mg prednisone) to eliminate the failures due to under-treatment ${ }^{50}$ but others ${ }^{51}$ advocate starting with low doses $(15 \mathrm{mg} /$ day).

\section{Table 3. Drugs and Toxins Deleterious to Neuromuscualar Junction and Aggravating Weakness in MG}

\section{Antibiotics:}

Neomycin (most toxic), Streptomycin \& Dihydrostreptomycin,

Kanamycin \& Gentamycin (moderately toxic) Tobramycin (least toxic); Viomycin, Bacitracin, Polymyxins A \& B, Colistin (somewhat toxic), Tetracycline, Oxytetracycline, Rolitetracycline, Lincomycin, Viomycin, Clindamycin, (somewhat toxic) via calcium chelation and post synaptic AchR block and possibly presynaptic blockade of NMJ; (Calcium and 4-aminopyridine can often reverse the effect).

Ampicillin $^{39}$

Toxins:

Bungarotoxin, Scorpion toxin, Wasp sting toxin, Tetanus toxin,

Crotoxin and Other elapid snake toxins

Botulinum toxin (clostridium botulinum); via presynaptic block of Ach release

Alpha latrotoxin (Black widow spider or Latrodectus Mactans and brown widow spider or Latrodectus Geometricus) via depleting the motor nerve ending from vesicles and getting inserted into the presynaptic membrane and preventing Ach reuptake

Paralysing tick toxin (North American tick or Dermacentor andersoni and Australian tick or Ixodes holocylus) via presynaptic inhibition of Ach release.

\section{Carbamate Anticholinesterases:}

Parathion, Malathion, Mipafox, Bagon, Isopestox, Sevin, Lannate, etc.

via irreversibly binding to enzyme AchE at AchR in addition to central and peripheral muscarinic and nicotinic Ach receptors and producing a depolarizing block from impaired Ach clearance from NMJ

NB: Pralidoxine displaces these agents from their binding to AchE and hence reduces Ach excess.

Anticholinergics:

trihexphenidyl, chlorpromazine, propantheline, etc.

Hormones:

Corticosteroids, ACTH, Thyroxin via reducing Ach release, altering choline transport and depleting intracellular potassium.

Sedatives (post synaptic):

Phenothiazines (chlorpromazine, promethazine), Narcotics.

Cardiac medications and contrast agents: Procainamide, Lidocaine, Quinidine, Propranolol, Oxyprenolol, Practolol, Timolol, Trimethaphan, Iothalamic acid of conray via both pre and post synaptic effects except Trimethaphan which acts postsynaptic only

via reducing the membrane excitability nonspecifically in addition to NMJ blockade. ${ }^{182}$ Beta-adrenergic blockers: interfere with the neuromuscular transmission (mechanism unknown).

\section{Anticonvulsants:}

Phenytoin, Mephenytoin, Trimethadione

via both a presynaptic Ach release impairment and post synaptic block.

\section{Direct membrane stabilizers:}

Chloroquine, quinine, quinidine, procainamide, xylocaine.

\section{Axonal transport inhibitors:}

Cisplatinum, colchicine.

Ions

Magnesium via impaired Ach release and reduced motor end plate sensitivity to Ach Lithium via impaired Ach synthesis and reduces the AchR density on motor end plate Potassium disturbances kalemic paralysis.

\section{Bulk laxatives}

(e.g.methylcellulose): via inhibition of absorption of AchE inhibitors. ${ }^{183}$

Other drugs which should be avoided

Morphine and related narcotics, barbiturate anesthetics, ketoprofen. ${ }^{184}$ 
We have found the following regimen quite safe where plasmapheresis is readily available. We hospitalize the patient for about a week and use a short course of plasmapheresis; we simultaneously initiate high dose steroids. Patients with severe dysphagia receive a nasogastric tube and are medicated intravenously and those with a safe swallowing are given high dose prednisone $(1.0-1.5 \mathrm{mg} / \mathrm{kg} / \mathrm{day})$ after the first day of exchange and that dose is maintained until remission is induced, which usually requires 3-12 weeks. Over the next 6-12 months, the patient is gradually changed to alternate day therapy with 100 $\mathrm{mg}$ and then tapered down to $30-50 \mathrm{mg}$ on alternate days. The anticholinesterase dose is tapered first to confirm remission. Tapering of steroids is stopped if weakness increases. Because clinical relapse of MG during steroid tapering takes 2-3 weeks to manifest, tapering is done slowly over 6-12 months.

Once on the alternate day regimen, some patients need a small dose ( 5 to $10 \mathrm{mg}$ ) on their 'off' day to remain asymptomatic (for example, $50 \mathrm{mg}$ on even days and $10 \mathrm{mg}$ on odd days). It is not clear if antibody levels can be used to monitor the steroid dosage, although a correlation between clinical improvement and decrease in antibody titres has been reported. ${ }^{40}$ The most striking drop occurs in the first 3 months..$^{52}$ Discontinuation of steroids carries an unacceptably high probability of a relapse assessed in one study at nearly $100 \% .{ }^{43}$ Oral steroids, therefore, should be regarded as life-long commitment with only a rare exception. A well-informed therapeutic decision must be made before starting steroids.

High dose intravenous steroids are also effective in MG with somewhat lesser early toxicity. ${ }^{53}$ Ten of the 15 patients of Arsura et al. with active MG given $2 \mathrm{~g}$ of IV methylprednisolone every 5 days improved after two infusions and 2 others after three infusions. Initial worsening was less than that with oral steroids and the remissions were induced more rapidly and with fewer side effects. Oral prednisone $(40 \mathrm{mg})$ is used to maintain the remission making IV steroids only an initial component of steroid therapy, but helpful in hospitals where plasmapheresis is not available.

High dose intravenous immunoglobulin, used with high dose intravenous methylprednisolone has been successful in treating refractory ocular as well as generalized MG..$^{54}$ Relapse ensued in a case treated with the above combination after seven months of initiation of the Ig therapy. Experience with IV IgG is limited and we personally have not used it at all.

Rarely can one go below 30-50 mg prednisone on alternate days. ${ }^{43}$ Early thymectomy may be a way to reducing overall use of steroids in MG. In our opinion, steroids are justified essentially for severe generalized MG. Steroids are generally not used for even severe ocular MG with the reasoning that the disease is not life-threatening while steroid therapy can be. Previous thymectomy does not eliminate likelihood of efficacy of subsequent steroid therapy although the magnitude of the effect has been reported to be dampened..$^{43}$ The complication rate of steroids is $66 \%$ and failure rate is $20 \%$, leaving less than $20 \%$ probability of benefit without serious side effects..$^{43}$

Long-term toxicity of steroids is inevitable. To minimize steroid-induced osteoporosis, calcium supplements, stanozolol, low dose estrogens, vitamin D, and ascorbic acid are suggested, although success appears limited. Incidence of GI hemorrhage has been reported up to $22 \%{ }^{33} \mathrm{H}-2$ receptor blockers have not been conclusively shown to be effective prophylactically against steroid-induced GI ulceration. Antacids are likely to interfere with the absorption of ChEls, hence their use is not advised. Cosmetic problems with development of Cushing's syndrome, and hyper-androgenesis can seriously limit female patients socially. Infections with uncommon pathogens are also to be expected because the immunosuppressive effects of high dose steroids are potent. In patients who have a high risk of complications from steroids, early introduction of cytotoxic immunosuppressors may be necessary.

Because steroid therapy, once started in MG, may need to be persued for years, we prefer to use it only after the failure of thymectomy. Although clinical improvement is nearly the rule after introduction of steroids, pressure to taper off the medication rapidly starts escalating. We find switching to alternate days at the time of partial clinical remission a good way of minimizing side effects. Rapid introduction of Azathioprine can help shorten the need for steroids.

\section{c) Azathioprine}

Azathioprine is a potent suppressor of primary antibody synthesis against several antigens but is ineffective against some thymus-dependent antigens such as TNP..$^{55}$ Thiopurines were the first agents used to induce tolerance. ${ }^{56}$ Although precise action of Azthioprine on Th cells remains obscure, a reduction of $\mathrm{Th} / \mathrm{Ts}$ ratio is seen. ${ }^{57}$ Atrophy of the thymic cortex is seen after using large doses of Azathioprine. ${ }^{56}$ Changes in in vitro immune function follow later. ${ }^{58}$

Mertens et al. have reported an 11-year experience with azathioprine $(2-3 \mathrm{mg} / \mathrm{kg} /$ day $)$ in 78 patients. ${ }^{59}$ Remission was complete in $31 / 78(40 \%)$, partial in $40 / 78(51 \%)$, and not seen in $7 / 78(9 \%)$. Worsening of MG did not occur. The clinical benefits had a latency of 2-3 months and peaked at 6-15 months. In their series, 30 patients were thymectomized and 21 received concurrent prednisone. Remarkably, no breakthrough weakness occurred during therapy in $8 / 18$ patients, Azathioprine could be discontinued without relapse - a great improvement when compared to steroids. Men, especially those over 35, showed maximal benefit.

Of 27 azathioprine-treated MG patients reported by Fonseca and Havard 1990, 4 needed discontinuation of treatment because of side effects but no patient had WBC count below $2.5 \times 10^{9}$, and none had opportunistic infections. The median dose of azathioprine was $100 \mathrm{mg} / \mathrm{day}$ and the mean duration of therapy, 7 years. Successful withdrawal was possible only in one patient after 5 years and another after 7 years of therapy. ${ }^{60}$ Improvement was impressive and azathioprine seemed to reduce hospitalizations. The toxicity of Azathioprine is not negligable although it is less than that of most other cytotoxic drugs (cyclophosphamide, mercaptopurine, actinomycin and methotrexate). Kissel et al ${ }^{61}$ have reported side effects which include pancytopenia ( 2 patients), mild leukopenia ( 16 patients), serious infection ( 2 patients), gastrointestinal irritation, and abnormal liver function.

It is our experience that at a dose of $3 \mathrm{mg} / \mathrm{kg} / \mathrm{day}$, half of the patients will experience problems and one-quarter to a fifth of patients may need discontinuation because of leukopenia. We adjust Azathioprine doses according to the results of frequent WBC counts. The dose is reduced to $50 \%$ when WBC drops to 
$<2800 / \mathrm{mm}^{3}$ or lymphocyte count to $<1000 / \mathrm{mm}^{3}$ and the drug is discontinued if the WBC drops below $1500 \mathrm{~mm}^{3}$ or lymphocyte count below $500 / \mathrm{mm}^{3}$ Whether Azathioprine adds to the clinical improvement after thymectomy is quite probable but has not been formally demonstrated. Macrocytosis is observed so regularly that we use it to monitor patient compliance. At UBC we test blood counts and liver functions weekly for 8 weeks and twice monthly thereafter. Patients are cautioned about the unproven possibility of slightly increased risks of malignancy, but this issue remains controversial. In a review of 104 patients, only one patient developed renal lymphoma after 6 years of azathioprine therapy, although 4 other patients developed malignancies which could not be attributed to the drug. ${ }^{62}$ Other studies report a 5 -fold increase in lymphoma with an incidence of 1:1000 patients/year and increased incidence of myeloma as well. ${ }^{63}$ We have observed a slight increase in neoplasm incidence in MS in a study monitoring $800 \mathrm{MS}$ patients/year. ${ }^{64}$ These patients received high doses of azathioprine $(3 \mathrm{mg} / \mathrm{kg} / \mathrm{day})$. Most limiting is a nonspecific febrile gastritis with fever, abdominal pain, nausea, vomiting and anorexia which reappears on re-challenge. This reaction indicates an absolute need for discontinuation. Mild but stable elevation of liver enzyme GGT (gamma glutamyl transferase) does not warrant drug withdrawal; but a sustained elevation of alkaline phosphatase is likely to lead to a micronodular cirrhosis and calls for discontinuation of Azathioprine. Although Azathioprine-induced hepatotoxicity is reversible on withdrawal, it recurs on re-challenge. An increased risk of glomerulonephritis has been seen with Azathioprine. ${ }^{65}$ Hepatotoxic agents and allopurinol are contraindicated in association. 66

Low morbidity figures reported from the centers who specialize in treatment of MG are often not achieved by physicians who only very occasionally treat patients with such cytotoxic drugs. ${ }^{67}$ Because of potential teratogenic effects from Azathioprine, pregnancy should be strictly and effectively avoided during therapy with Azathioprine even though we have seen some uncomplicated pregnancies start while Azathioprine was used for treatment.

\section{d) Cyclosporin A (CsA)}

In transplantation, even a short course of Cyclosporin A can induce a long lasting or permanent tolerance to the graft. ${ }^{68} \mathrm{By}$ extension, if a short course of this drug could restore tolerance towards AchR it would prove to be curative in MG. Experimentally, cyclosporin A not only prevents induction of EAMG, it also suppresses the ongoing and secondary responses. ${ }^{69} \mathrm{CsA}$ presumably acts by selective inhibition of the production of IL2 and other growth factors essential for B cell and proliferation of $\mathrm{T}$ helper cell. ${ }^{70} \mathrm{CsA}$ is an attractive alternative immunosuppressant with a different mechanism of action from Azathioprine but its immunologic effects and toxicity profile are well studied in organ transplantation. ${ }^{70.71}$ It inhibits amplification of the immune response mediated by Th cells. ${ }^{72}$ Although its clinical efficacy has been demonstrated by Tindall et al. ${ }^{73}$ and suggested to be comparable to Azathioprine, the high incidence of nephropathy remains a major limitation.

An ongoing multicenter trial in the United States should bring more detailed data on the efficacy of CsA. Our limited experience ( 3 patients) with CsA, used only in patients who were unresponsive to long term steroids, azathioprine and weekly plasmapheresis, has been very encouraging with a substantial fall in antibody titres and induction of a remission which was not otherwise attained. Easy access to drug level monitoring has made following such patients easy; we have found drug levels of $100-150 \mathrm{ug} / \mathrm{L}$ to be well tolerated and to show a good efficacy in our limited experience.

\section{e) Cyclophosphamide}

Cyclophosphamide is useful in experimental MG but at myelosuppressive doses only. ${ }^{74.75}$ In human MG, unacceptable side effects like alopecia, cystitis and threat of bladder cancer ${ }^{76}$ make it difficult to justify the use of this drug because safer agents like Azathioprine and CsA are effective. Risk: benefit ratio of cyclophosphamide is quite poor for its use in MG. A single study reported modest success of this drug in $\mathrm{MG}^{77}$ and its efficacy in MG has not been compared with that of Aza or Cyclosporin A.

\section{f) Plasmapheresis or Plasma exchange (PE)}

Plasmapheresis is very effective in removing macromolecules, including $\mathrm{IgG}$, with rapid and dramatic recovery from $\mathrm{MG}$ even in crises. Plasmapheresis is very effective in lowering antibody titres and results in short lived (4-6 week long) clinical improvement. ${ }^{78-81}$ At least one randomized study shows the efficacy of this modality. 82

Unfortunately, PE also stimulates the immune system, as shown by a rebound in antibody synthesis ${ }^{83}$ and increases autologous mixed lymphocyte reaction (AMLR) - a measure of autoimmune activity. ${ }^{84}$ Therefore, it seems logical to use plasmapheresis only for short-term indications like pre-thymectomy ${ }^{85}$ or while initiating oral steroids. Combining it with high dose IV methylprednisolone may effectively prevent rebound stimulation; if it is to be used, immunosuppression should be added to reduce immune function stimulation. Long-term use of serial plasmapheresis is very exceptionally indicated in thymectomized MG patients and only if steroids and immunosuppressors fail or side effects prevent their use. Plasmapheresis can be limited by poor venous access, in which case shunt catheters must be inserted. Its use is limited by the restricted availability and high expense. PE is effective even in the absence of precipitating antibodies i.e. in the sero-negative MG patients. ${ }^{86}$

Daily or alternate day regimens of PE with 3-5 sittings with exchange of about 1 intravascular volume $(50-60 \mathrm{ml}$ of plasma/ $\mathrm{kg}$ ) are used. ${ }^{87}$ All reports, although uncontrolled and unblinded, show good results concomitant with a drop in antibody titres. ${ }^{88}$ When patients are receiving high dose IV methyl-prednisolone along with PE, infusions should not be given just prior to the exchange. Because anticholinesterases are not removed in substantial amounts by PE, dosing of these drugs needs no adjustment. In an exceptional patient, PE may be the only modality to which response can be observed. Even then this therapy can be recommended only if it is expected to be required only a few times in a year. ${ }^{89}$ Other modalities must have been exhausted before resorting to long term PE. ${ }^{80.90}$ Five daily exchanges every 5 weeks is one of the long term regimens suggested in such cases. We do not advocate such a regimen and recommend increasing steroids, adding Cyclosporin A or Azathioprine instead.

Extracorporeal immunoadsorption is still at the experimental stage; Protein A bound to Sepharose has been shown to be 
effective in several other auto-immune disorders. In a full scale in vitro experiment, removal of $43 \%$ of $\mathrm{AChR} A b$ was possible in 70 minutes. ${ }^{91}$

\section{g) Thymectomy}

The association between thymus and MG was first noted by Weigert ${ }^{92}$ in 1901. In 1913, Schumacher and Roth $^{93}$ reported clinical improvement from thymectomy in MG coexisting with hyperthyroidism. This operation was applied by Alfred Blalock in 1939 to a patient with thymoma ${ }^{94}$ and later extended to $\mathrm{MG}$ patients without thymoma. ${ }^{95}$ The thymic abnormalities, in the form of thymic hyperplasia or thymoma, are seen in most MG patients. ${ }^{96.97}$ In hyperplasia and around thymoma, the thymic medullary epithelium is frequently hyperplastic, and lymphoid follicles with active germinal centers occur in the thymic medulla. ${ }^{96}$ These cells have been shown to secrete antibodies. ${ }^{98}$ The thymus also contains "myoid" cells which have been shown to contain extrajunctional AChRs. They are present not only in patients with MG but even in healthy subjects. Thymic "myoid" cells are believed to be a source of antigen in MG, but the most recent and detailed histological data on these cells suggest that the myoid cells are not the primary source of immunogen. ${ }^{99} \mathrm{Of}$ interest is the fact that thymus has not been found to be abnormal in EAMG suggesting that thymic abnormalities are not secondary to the disease. Thymectomy is the most effective and the safest therapeutic modality aiming at curing MG. ${ }^{100}$ In Simpson's early results between 1934 and 1956, 29\% non-thymectomized MG patients died of MG while, only 5 to $10 \%$ thymectomized patients did. Thymectomy was done for thymoma but mostly for follicullar hyperplasia. ${ }^{101}$ No controlled clinical trial has been attempted to answer the various questions that arise in relation to thymectomy. Present day conclusions on the effect of thymectomy are based on the retrospective analysis of Perlo et al. ${ }^{102}$ and of Grob et al. ${ }^{6}$

Initially thymectomy was done only for thymomas and the presence of thymoma remains an absolute indication for thymectomy. Surgical excision prevents local spread of the tumors but sometimes the procedure may not improve neuromuscular transmission substantially. ${ }^{101}$ Conventional chest tomograms detect most thymomas but rarely thymic hyperplasia. Their poor sensitivity has made them obsolete. Although CT scanning and MRI are very sensitive in detecting thymomas, thymic hyperplasia can be misinterpreted as neoplasm; and reliable criteria helpful in predicting the histology from imaging studies do not exist. CT scan may be too sensitive to be a screening tool. ${ }^{103}$ Hyperplasia can appear as a nodule on imaging. Young patients suspected to have thymoma have turned out to have normal thymus or hyperplasia. Therefore, the presence of "anterior mediastinal mass" alone is not always indicative of thymoma. Radionuclide imaging techniques ( ${ }^{67}$ Gallium) have been used but they too do not reliably differentiate thymoma from hyperplasia. ${ }^{104}$ Although long-term follow-up showed that serum AChR Ab titres decrease and clinical improvement follows thymectomy, one cannot be certain that a similar reduction in antibody would not have occurred without thymectomy. ${ }^{105.106}$ Thymectomy is claimed to be safer than medical immunotherapy ${ }^{67}$ and this is our experience after over 50 thymectomies. ${ }^{107}$

Removal of cells which are secreting antibodies has therefore been offered as a possible explanation particularly in view of the rapidity of improvement after thymectomy. The thymus does selectively trap sensitized cells especially the AchR sensitized cells which secrete AchR Ab. ${ }^{108}$ Although the amount of AChR $\mathrm{Ab}$ produced in the thymus represents only a fraction of the total antibody production, lymphocytes from myasthenic thymus glands produce substantial amounts of $\mathrm{AChR} \mathrm{Ab}$ in vitro. ${ }^{109.110}$

Only indirect evidence suggests that thymectomy suppresses antibody synthesis. 1) Antibody titres drop after thymectomy. 2) Seronegativity is higher in series of thymectomized patients, especially if thymectomy is done early. 3) Rate of neonatal MG was $6 \%$ in newborns of thymectomized mothers compared to $12 \%$ in those who did not have a thymectomy prior to pregnancy. 11

We can confirm that thymectomy also improves seronegative MG. Even in this subgroup, thymus somehow contributes to the neuromuscular dysfunction. We suggest it is probably by a mechanism other than AchR Ab. ${ }^{107}$ Thymectomy, therefore, should not be withheld even in seronegative MG patients although a dramatic result or complete remission is less likely than in hyperplasia.

Why does thymectomy induce a remission only in MG and not in other auto-immune diseases? Thymectomy indeed reduces the occurrence of associated auto-immune disease in patients with MG; when associated with SLE or thrombocytopenia ${ }^{112}$ the course of both was favorably influenced. A few reports of benefits of thymectomy in multiple sclerosis ${ }^{113}$ and other auto-immune diseases ${ }^{114}$ also exist. Experience with thymectomy in auto-immune diseases other than MG is scarce and thymectomy may emerge as a useful adjunct in those diseases as well. Exceptionally, MG is worsened after thymectomy. ${ }^{115} \mathrm{MG}$ can also reappear long after apparent cure of invasive thymoma and be secondary to an isolated metastasis ${ }^{116}$ suggesting a complex relationship with $\mathrm{MG}$.

Results: Nearly all patients treated with thymectomy alone obtain some benefit; complete remission occurs in 10-15\%, partial remission in nearly $50 \%$ and some degree of improvement in $30 \%$. In non-thymomatous MG, thymectomy is successful in inducing remission in nearly $80 \%$, although a latency of up to 510 years has been noted. No postoperative deaths or increase in severity of symptoms or medication requirement is usually seen with uncomplicated thymectomy in the recent literature. ${ }^{117}$ There is no evidence for a deleterious effect of thymectomy on the function of the immune system, in adults and juveniles with MG. The roles of the thymus and thymectomy may not be simple and MG has been seen to develop after thymectomy. ${ }^{118}$

In generalized $\mathrm{MG}$, thymectomy hastens the onset and increases the frequency of remissions. ${ }^{5,105,119-121}$ The peak effect of thymectomy is noted after 3 years. Antibody titre reduction or disappearance has also been noted. Remission rate drops below $35 \%$ if one waits for more than 1 year after the diagnosis. ${ }^{122}$ Young women with mild symptoms, hyperplastic glands and high antibody titres have the best chance of a remission. ${ }^{122.123}$ Grob et al. ${ }^{6}$ suggest that thymectomy should be limited to the more seriously ill patients. Between 1960 and 1980, 121 of their 476 patients underwent thymectomy ( 355 did not). The thymectomized patients had only a slightly higher rate of improvement ( $41 \%$ for males and $42 \%$ for females) than the non-thymectomized group (34 and 40\%) and mortality was only slightly lower ( 8 and $13 \%$, compared with 16 and $10 \%$ ). With improved respiratory care and corticosteroids, even seriously ill patients have generally done well even without thymectomy. ${ }^{6}$ Because 
this too is not a randomized study, we suspect that selection was biased towards doing thymectomy in more seriously ill patients thus minimizing the benefits of thymectomy.

There is little doubt that trans-cervical approach is better tolerated than trans-sternal approach ${ }^{124}$ but because remnants of thymus are widely distributed in the neck and mediastinum, an en bloc transcervical-transsternal "maximal" thymectomy has been suggested in order to remove all thymic tissue with reasonable certainty. When a relapse occurs, the anxiety of having left some lymphoid tissue capable of producing antibodies could lead to a second operation via sternal-splitting approach. Thymomas may develop after a trancervical thymectomy. ${ }^{125}$

Short term results of the trans-cervical approach were reported to be equivalent to the trans-sternal approach. However, relapses are more common after trans-cervical approach and will become manifest upon long term follow up only. The controversy about the surgical technique has been resolved in the favour of transsternal approach popular in most institutions. We recommend trans-sternal approach for completeness of thymectomy because the logical goal of thymectomy is total extirpation. ${ }^{126}$ Irrespective of the approach, results reported in the literature are to be expected only if the operation is conducted at specialized centers with extensive experience.

Early thymectomy is currently recommended for adult MG patients with generalized as well as bulbar MG of moderate to severe degree. ${ }^{127}$ There is no clear cut basis not to recommend a similarly aggressive approach in mild generalized MG patients and even in purely ocular forms. Thymectomy does not eliminate the need for future immunosuppressive therapy. In the series of Donaldson et al. ${ }^{11} 58 \%$ of thymectomized and $53 \%$ of un-operated MG patients required immunosuppressor therapy. It is possible that more severe patients were subjected to thymectomy. In our personal experience, out of 48 thymectomized patients only $12(25 \%)$ needed steroids. Completeness of thymectomy may underlie this disparity. Extrathymic sources of antibodies almost certainly exist.

Most neurologists are in favour of early thymectomy ${ }^{128}$ in generalized MG, although differences of opinion exist. Juvenile MG patients (onset before age 15) are generally not subjected to thymectomy but the procedure is helpful even in this group and it is advised if steroids appear to be needed to control $\mathrm{MG}$, as growth retardation due to steroids can be devastating in children. Because anesthetic risk and surgical mortality have been essentially eliminated, thymectomy must be given a serious consideration even in very old patients. ${ }^{6.129}$

MG patients are best prepared for thymectomy by a short course of plasmapheresis ${ }^{130}$ or courses of high dose oral ${ }^{131}$ or intravenous steroids ${ }^{53}$ given immediately preoperatively. Such a preparation reduces the risk of developing a myasthenic crisis or pulmonary complications from $10 \%$ to near zero and insures good outcome of surgery. ${ }^{119.132}$ Patients given preoperative steroids must continue to receive those postoperatively to prevent adrenal crisis. Following the combination of plasmapheresis and thymectomy, many patients reach complete clinical remission but this often lasts only 1-3 weeks. Post operative thymic irradiation is considered in patients with thymoma in whom excision was incomplete. Simpson stresses that overdosage of anticholinesterase, rather than complications of surgery, contribute to postoperative mortality. ${ }^{67}$ The requirements for anticholinesterases fluctuate widely post-operatively.
In fact, transient improvement in the status of these patients is so frequent that anticholinesterases can be withdrawn in the postoperative period. Mechanism of this short-lived post-operative improvement is unknown. A clinical evaluation soon after surgery is required to determine when anticholinesterases need to be re-introduced. ${ }^{133}$ We routinely perform an edrophonium test before restarting anticholinesterases. The muscarinic effects of ChEls, such as bronchorrhea and sialorrhea, can impede respiratory function in the postoperative period.

\section{h) Splenectomy}

To further reduce the number of antibody-secreting cells, splenectomy, has been advocated by Hofmann et al. in patients who do not respond to thymectomy. ${ }^{134}$ Splenectomized patients with MG face a high risk of similar fatal pneumococcal septicemias to splenectomized Hodgkin's disease patients. ${ }^{135}$ Postsplenectomy immunization is strongly recommended. Partial success has been occasionally reported in MG patients given splenic irradiation with or without whole-body irradiation. ${ }^{136}$

\section{i) Intravenous immunoglobulin or IVIgG}

High-dose IV immunoglobulin therapy $(20-40 \mathrm{mg} / \mathrm{kg}$ ) has been recently introduced in US and Canada after trials in Europe. Arsura et al. have reported the largest trial using IVIgG as an adjunct to steroids. ${ }^{137}$ Unfortunately, here too these trials have been open. Several ( 2 to 5 ) courses of intravenous immunoglobulin (IVIg) are given at the onset of an exacerbation of generalized MG with minimal side effects and no significant change in AchR Ab titres. IVIg does not exhibit loss of efficacy with repeated use and this makes it a useful adjunct in the management of refractory MG. ${ }^{138}$ Maruyama et al. observed complete clinical remission with disappearance of $\mathrm{Ach} \mathrm{R} \mathrm{Ab}$ in a girl with ocular MG resistant to conventional anticholinesterase drugs. ${ }^{139}$ But for its prohibitive cost, IVIgG looks promising because it has a distinct efficacy and very favorable side effect profile. The mechanisms underlying clinical improvement remain obscure. Postulated mechanisms include: (1) competition with AChR Ab for binding with AChR; (2) prevention of attachment of $\mathrm{Fc}$ receptor-positive inflammatory cells to $A C h R A b$ bound to the motor end plate; (3) exertion of an anti-idiotypic effect; ${ }^{140}(4)$ stimulation of suppression. ${ }^{141}$

\section{EXPERImENTAL and Future Therapies}

Over the last decade, technological advances have included novel avenues like sequencing and cloning of the protein subunits of $A c h R^{142.143}$ permitting exploration of the effect of nonsensitizing sequences on the immune response. The development of EAMG as an experimental model for studying the pathogenesis and testing of new therapies for MG has provided a useful paradigm. However, EAMG, unlike MG is not a selfsustained auto-immune process.

\section{a) Selective immunoadsorption}

Selective immunoadsorption therapies can be developed to accomplish substantial removal of specific antibodies. Using AchR fixed to adsorption columns would lead to selective removal of $A c h R A b$ but the amounts of antigen needed are greatly in excess of what can be produced. Production of vast quantities of antigen can only be done by genetic engineering and its yield is still insufficient. It could prove too costly to be practical, and is not a curative procedure. 


\section{b) Monoclonal antibodies}

Immunization of rabbits with purified $\mathrm{AChR} A \mathrm{~b}$ induces a polyclonal anti-idiotypic $A C h R A b$ response and partially prevents the induction of EAMG by $\mathrm{AChR} .{ }^{144}$ In contrast, severe EAMG develops on immunization with $A C h R$ of rats that had a high titre of anti-idiotypic antibody to a monoclonal AChR Ab. ${ }^{145}$ Monoclonal antibodies (Mab) have also been developed in experimental designs that can prevent EAMG. Mab have been successfully used to finely dissect the antigenicity of the subunits of the AchR. They can also be used to block Ab binding to the antigen (anti-idiotypes) or tagged to a toxin, help destroy cells which have been sensitized against the antigen.

\section{c) Radioactive antigen suicide}

In this approach ${ }^{125}$ I-labeled antigen of high specific activity destroys lymphocytes binding (i.e. responsive) to that antigen. This system has been effective in animals in preventing EAMG. ${ }^{146}$ Similarly it suppresses the development of experimental autoimmune encephalomyelitis, and auto-immune hepatitis. ${ }^{147}$ This approach may be difficult to extend to an ongoing auto-immune disease with high titres of circulating autoantibodies, where a radioactive antigen would be rapidly cleared.

\section{d) Immunotoxins}

Recent work has focused on the development of specific immunotoxins which would eliminate restricted populations of cells. ${ }^{148-151}$ Plant or microbial toxins bound to antibodies or antigen will recognize a subpopulation of cells and destroy it. ${ }^{152}$ Native ricin molecules ${ }^{150}$ and ricin A chain ${ }^{153,154}$ have been used as immunotoxins with some success in in vitro studies. HoloricinAChR conjugates suppress $B$ cell antibody synthesis in lymph node cultures from EAMG rats following addition of AChR to the culture. ${ }^{155}$ Ricin A chain-AChR conjugates have similar effects against isolated lymphocytes and produce suppression of both proliferation of $\mathrm{T}$ cell and antibody production by $\mathrm{B}$ lymphocytes. ${ }^{156}$ After covalent linkage to Mabs, the ribosomal-inactivating proteins gelonin ${ }^{157.158}$ and saporin, ${ }^{159}$ acquire potent and specific cytotoxic activity in other systems.

Chemotherapeutic agents such as daunomycin (DM) have also been tagged with antigens or antibodies with some success. ${ }^{160-162}$ Diener et al., ${ }^{163}$ showed that DM tagged with hapten conjugates of ovalbumin caused hapten-specific immunosuppression of murine B cells in vitro and in vivo. From $50 \%$ to $90 \%$ suppression of $\mathrm{AChR}$ Ab production was observed, without any $T$ cell response suppression, when sensitized lymphocytes from rats immunized with $\mathrm{AChR}$ were co-cultured with DM-AChR conjugates in a ratio of 40-60:1. The immune response to keyhole limpet hemocyanin (KLH) was not suppressed, indicating the selectivity of the process. DM-KLH conjugates did not affect the response to AChR. Despite good success in prevention of EAMG by pre-treatment with DM-AChR, attempts at treating chronic EAMG or MG with toxin conjugates are expected to be technically much more difficult.

\section{Difficult Management Problems in MG Patients}

\section{a) Management of mild generalized MG}

We recommend that all patients with generalized MG even when disease is mild be thymectomized early in the course of disease except if contraindications exist. Chances of inducing a remission are reduced with older age ${ }^{164}$ and thymectomy is the only way of ruling out a thymoma and treating it early if it is present.

\section{b) Refractory ocular MG}

Thymectomy is claimed to be effective even in ocular MG. Long-term oral steroids have also been used in some patients. While some neurologists apply all the principles of generalized MG to the treatment of ocular MG, most are more conservative. We would tend to apply thymectomy and possibly steroid therapy to ocular myasthena. We emphasize the need for careful discussion of risk: benefit ratio with the patient especially in young individuals with special professional circumstances (truck drivers, mechanics, etc.). We are comfortable with this approach early in the disease as a proportion of these patients will exhibit generalized MG.

\section{c) Refractory generalized MG}

At times, situations arise in which weakness persists in thymectomized MG patients who are on large doses of oral steroids, anticholinesterases (usually pyridostigmine) and on Azathioprine. These patients need to be investigated for concomitant polymyositis, Eaton Lambert syndrome, hyperthyroidism, hypothyroidism, steroid myopathy or a concomitant neuropathy or myelopathy (especially epidural lipomatosis from steroids). Some other measures we would suggest include:

1) Addition of neostigmine instead of increasing pyridostigmine beyond a dose of $360 \mathrm{mg} /$ day. This combination can be easily titrated and does not have the risk of cumulative toxicity i.e. cholinergic crisis.

2) Re-exploration of the mediastinum. CT scan, MRI or radio-isotope scans of the chest are not sufficient to rule out thymic recurrence. ${ }^{165}$ When severe symptoms persist after previous trans-cervical or submaximal trans-sternal resections, reoperation by the combined technique should be considered. Jaretzki et al. reported a group of 8 non-thymomatous MG patients, who underwent re-exploration for incapacitating weakness after thymectomy; residual thymus was found in all. Remission or variable degree of improvement was noted after the re-exploration without worsening in any case. ${ }^{166}$

3) Trial of new immunosuppressants such as cyclosporin-A.

4) Repeated courses of plasmapheresis. This should be used as a last measure and only while waiting for maximal immunosuppression to become effective.

In refractory patients we measure antibody levels repeatedly to guide us in evaluating the effect of changes in therapy.

\section{d) MG with concomitant problems}

Poor control in some MG patients has been attributed to a concomitant hyper or hypothyroidism. We have seen coexistence of dysthyroid ophthalmopathy and ocular MG posing difficult problems both of diagnosis and treatment. Plasma exchange, antithyroid medications and orbital irradiation had to be used simultaneously. Thyroid disorders are seen in up to $13 \%$ of patients with $\mathrm{MG},{ }^{167}$ and pathophysiological observations of defects in the neuromuscular transmission have been made in hyperthyroidism alone. ${ }^{168.169}$ Myasthenics with diabetes are difficult to control when treated with steroids and very early use of cytotoxic immunosuppressors is indicated here. Coexistence with Eaton Lambert syndrome is rare and is likely to go undetected 
unless immunological markers for both MG and LEMS are used. Whether some patients have a mixture of the two is debatable.

\section{e) MG and Respiratory Failure}

Respiratory depression following surgical procedures is the most common and best documented manifestation of druginduced neuromuscular blockade. ${ }^{170}$ Whatever the origin of respiratory distress, intubation and mechanical ventilation need to be initiated before carbon-dioxide accumulation begins. As soon as the vital capacity is compromised, patients should be prepared for ventilatory support. If transportation is necessary, it should be done by a special paramedic team.

Acute respiratory failure is the most dreaded complication of MG and can result from an exacerbation of the disease or inadvertent cholinergic overdosage. ${ }^{32.171}$ Because patients with respiratory compromise are likely to have an impaired deglutition reflex, acute respiratory failure may be precipitated by aspiration. It can also result when an increased load is placed upon the already compromised ventilatory muscles (for example, by pneumonia). Mortality in patients with respiratory failure is lower when due to MG than when due to other causes and patients do not become ventilator dependent. Most of them come off the ventilator within 7-10 days. ${ }^{172.173}$

Lung volumes tend to be preserved until late in patients with MG. A decrease in vital capacity of $50 \%$ occurs when the respiratory muscle strength is approximately $30 \%$ of normal. Residual volume is typically increased because of the inability of the weak intercostal and abdominal muscles to exhale maximally. Maximum voluntary ventilation (MVV) tends to be less than $50 \%$ of that predicted in patients with MG who are apparently well. In the absence of concomitant lung disease, a restrictive pattern is seen on lung function test with a reduced vital capacity and a relatively preserved functional residual capacity. Expiratory muscle weakness (e.g. abdominal, intercostal muscles) can lead to an elevation in residual volume.

Maximum inspiratory pressure (MIP), maximum expiratory pressure (MEP) and vital capacity are useful indicators and can be combined with the Tensilon test to distinguish cholinergic from myasthenic crisis. MIP and MEP are more sensitive for detecting ventilatory weakness than lung volumes. A maximal inspiratory pressure of less than $30 \%$ of that predicted for size and age is a sign of severe compromise and indicates either the need for very close monitoring or initiation of ventilatory support. A reduction in maximal expiratory pressure correlates well with a decrease in cough, resulting in increased risk of infection and decreased secretion clearance.

Although the technique for measurement of MIP and MEP is straightforward, not all laboratories have the ability to perform these measurements. Furthermore, they are effort-dependent and optimal patient cooperation must be insured. In addition, orbicularis oris weakness is common in myasthenics and leakage of air around the mouthpiece can lead to an underestimation of respiratory muscle strength. Therefore, when the accuracy of these measurements is uncertain, concomitant measurement of the vital capacity should be performed.

Arterial blood gases are not a reliable way of monitoring patients with MG because the carbon dioxide level can remain deceptively normal until just before respiratory arrest. ${ }^{173}$ There is a wide inter-subject variability in $\mathrm{PCO}_{2}$ for a given level of ventilatory muscle weakness. In some individuals a normal
$\mathrm{PCO}_{2}$ may be maintained with reductions in respiratory muscle strength to $15 \%$ of predicted values. Patients unable to clear their secretions need ventilatory assistance to prevent acute respiratory arrest. ${ }^{174} \mathrm{MEP}$ below $40 \mathrm{~cm}$ of $\mathrm{H}_{2} \mathrm{O}$ (i.e., less than $30 \%$ of predicted) is a very reliable indication of the need for ventilatory assistance. In the absence of MEP, a vital capacity of less than $15 \mathrm{ml} / \mathrm{kg}$ body weight (approximately one litre for an adult) can be used as well. ${ }^{174}$

Conventional mechanical ventilation techniques are used for patients who become ventilator-dependent with MG. There has been no substantiation of a benefit in weaning parameters using either increasing trials of spontaneous breathing interspersed with ventilatory support, or a slow reduction in the number of ventilator breaths delivered per minute (IMV weaning). Given the fact that MG patients rarely require long term ventilation, a tracheostomy is generally not necessary. More recently, use of a non-invasive positive pressure ventilator (nasal PPV) has shown promise in stabilizing the respiratory status of patients without requiring endotracheal intubation. The airway access in this technique is via a nasal mask. Positive end expiratory pressure (PEEP) is very helpful in patients in respiratory failure from MG. It permits resting of the respiratory muscles and expedites weaning. Other measures that we apply to patients in crisis involve change in anticholinesterase doses and plasmapheresis. Although overdosage of anticholinesterases occurs, and even if it is possible that the patient has a myasthenic crisis and is under-treated, once ventilation has been initiated, anticholinesterases should be withdrawn for 24-48 hours as soon as the patient is being ventilated.

It is in the presence of acute respiratory failure that differentiation of cholinergic from myasthenic crises is of major importance. The effects of the edrophonium test on the vital capacity usually can also be used as a helpful test in this situation. Daily plasmapheresis for 5 days will promptly restore sensitivity of the receptors to Ach. While re-introducing anticholinesterases, syrup or suspension of pyridostigmine via NG tube is better and safer than parenteral anticholinesterases.

\section{f) MG patients with Infections}

MG patients need to exercise special caution when they get upper respiratory infection and need to stay close to a source of medical care. The dose of anticholinesterases may need to be increased for short time. Aminoglycosides (especially neomycin) and polypeptide antibiotics (polymyxins and colistin) should not be used as they block neuromuscular transmission and worsen MG. Although not as serious as aminoglycosides, reports of ampicillin, tetracyclines, lincomycin and clindamycin making MG worse also exist. Penicillins, cephalosporins and erythromycins are safe in MG.

\section{g) Pregnant MG Patients}

Pregnant myasthenics have poorer exercise tolerance during pregnancy and a slower progress of labor. Anesthetic risk is exaggerated if Cesarian section is required. A spinal anesthetic is safer for these patients. Post-Cesarian acute respiratory failure should be suspected to be due to occult MG until investigations exclude that possibility. Pregnancy and a prolonged labor and warmth worsen weakness and muscle relaxants used during anesthesia and antibiotics used postoperatively can precipitate respiratory failure. ${ }^{174}$ The neonate has $10 \%$ risk of having 
neonatal MG because the AchR Ab is IgG and can enter the fetus in substantial amounts.

\section{h) Neonatal Myasthenia}

A small proportion of babies born to myasthenic mothers will develop a self limited illness at birth or in the first 48 hours. This includes feeble cry and facial weakness producing difficulty in sucking and feeding. Swallowing difficulties can also be recognized. Less often $(65 \%)$ there is generalized weakness and respiratory distress. ${ }^{175}$ Ptosis and extra ocular muscles involvement are difficult to recognize. The disease recovers spontaneously in 1 to 6 weeks almost invariably without sequellae. Some of these children need ICU transfer and ventilation. They respond to acetylcholinesterase inhibitors. Once remitted, the condition does not tend to recur. Undoubtedly the disease is secondary to transplacental transfer of AchR Ab. It is classically said that severity and duration of the disease state do not parallel the severity of the disease in the mother nor the AchR Ab levels in both mother and baby (they are quite similar as the antibodies are IgG. It is rarely that seriously affected MG women will become pregnant and the few pregnant patients (6) that we have followed were all in complete clinical (but not immunological) remission. Their babies were not affected even though they had circulating AchR Ab. These pregnancies were considered high risk and delivery took place close to a specialized centre.

\section{i) Congenital Myasthenia}

This is a rare condition, generaly recognized at birth in babies born from non-myasthenic mothers; it is often familial. There is marked involvement of the ocular musculature. This disease does not remit but is rarely life-threatening and may even be benign. There are no circulating antibodies.

\section{j) Juvenile Myasthenia Gravis}

A certain proportion (5 to $10 \%$ ) of patients with acquired, immune mediated myasthenia gravis will have onset of their disease in childhood. Together with Oosterhuis ${ }^{176}$ we consider this form of MG to be similar to the adult form. The disease may be typical but it is said to be more frequently familial, to have more severe opthalmoplegia, to have slower progression and higher proportion of spontaneous remissions. The same proportion of patients are antibody positive as in adult MG. Therapy is similar to what has been reviewed for adult MG but the use of steroids is restricted by growth considerations and it is only reluctantly that neuropediatricians will recommend thymectomy.

These forms of acquired immune MG starting early in life should be differentiated from some late onset forms of congenital myasthenia which would fit better in the group of myopathies. Some of these myopathies affecting the neuromuscular junction may have some electrical and pharmacological similarities with immune MG but they do not have antibodies. This group of disorders is being actively explored by Engel and associates. ${ }^{177}$

\section{k) Elderly Patients with MG}

Patients above age 70 may be difficult to diagnose, they may be diagnosed as having bulbar involvment secondary to stroke or amyotrophic lateral sclerosis. Some with mainly respiratory involvement have been diagnosed as 'COPD'. A high index of suspicion is necessary to reach a correct diagnosis. Even in elderly patients thymectomy must be given a serious consideration as it can be safer than steroids. We tend to start these patients very early on Azathioprine as it is much better tolerated in the elderly than steroids.

\section{l) Seronegative MG}

A small group of patients exists in which present techniques fail to identify the presence of circulating antibodies ('antibody negative' or 'seronegative MG'). It is likely that half of them do have antibodies which are hard to identify but it is possible that the other half may be mediated by non-antibody factors. A mother and child pair "seronegative" by radioimmunoassay 178 has been reported demonstrating that even seronegative human MG can be passively transferred when antibodies are undetectable. ${ }^{179}$ Similar passive transfer of $\mathrm{MG}$ in animals has been demonstrated by Mossman et al. ${ }^{180}$ Thymic abnormalities are rare among patients with "seronegative MG". We found only $25 \%$ of seronegative generalized MG patients to have thymic abnormalities, whereas $71 \%$ of seropositive patients did. All thymoma patients were seropositive ${ }^{107}$. We think that patients without circulating antibodies that precipitate $A c h R$ and without thymic abnormality constitute a small but very important subgroup of myasthenics which is important in understanding the pathophysiology of $\mathrm{MG}$, because these patients are an outstanding exception to the antibody hypothesis. ${ }^{107}$ The absence of antibodies should not deter one from making the diagnosis of MG although in these patients one has to rely more heavily on the clinical and electrophysiological features. We find that seronegative MG patients do respond to all therapeutic measures used for seropositive $\mathrm{MG}$, although their response is in general less complete.

\section{Concluding Remarks}

The first important advance in the therapy of MG was the use of ACh esterase inhibitors: this occurred when Mary Walker reported her highly successful non-blinded, uncontrolled trial of physostigmine in a patient with MG. ${ }^{181}$ The site of the lesion was only suspected and its mechanisms unknown. With the evidence of the auto-immune nature of $\mathrm{MG}$ it is now possible to design specific approaches for suppressing the auto-immune response to $A C h R$ in $M G$ even without full knowledge of its detailed pathogenesis. An optimal treatment of MG should selectively, completely and permanently eliminate the abnormal auto-immune response against the AchR. Reality has not reached these ideals. $A$ vast number of therapeutic options are now available but intensive respiratory care, thymectomy and anticholinesterases have made a major impact on the natural course of MG, rendering many myasthenics able to lead a fully productive life. Most, nevertheless, still require medication with steroids and cytotoxic immunosuppressors. With this therapeutic armamentarium the vast majority of MG patients can now reach complete clinical remission. It is not known however if these patients are more at risk of recurrence than those who reach clinical and immunological remission but we would suggest that this could very well be the case.

\section{ACKNOWLEDGMENT}

This review is dedicated to Ludmilla Zeldowicz for her vibrant energy. The help of Tariq Aziz and Anne Schaffar is gratefully aknowl- 
edged. We thank the Muscular Dystrophy Association of Canada, the Myasthenia Gravis Foundation of Vancouver and Myasthenia Gravis Foundation of Victoria for their generous support. P.Verma was a fellow of the MDA of Canada.The generous support of University Hospital Foundation in Vancouver is recognized.

Abbreviations: alphaBT, alpha-bungarotoxin; Ab, antibodies; AchR, acetylcholine receptors; EAMG, experimental auto-immune myasthenia gravis; LEMS, Lambert Eaton myasthenic syndrome; mAb monoclonal antibody; MG, myasthenia gravis; NMJ, neuromuscular junction.

\section{REFERENCES}

1. Ravits J. Myasthenia gravis. A well-understood neuromuscular disorder. Postgraduate Medicine. 1988; 83: 219-223.

2. Campbell H, Bramwell E. Myasthenia gravis. Brain 1900; 23 : 277-336.

3. Kennedy FS, Moersch FP. Myasthenia gravis. A clinical review of 87 cases observed between 1915 and early part of 1932. Can Med Assoc J 1937; 37: 216-223.

4. Simpson JA. Myasthenia gravis: a clinical approach to pathogenesis. In: Lunt GG, Marchbanks RM, eds. The Biochemistry of Myasthenia Gravis and Muscular Dystrophy. London: Academic Press, 1978; 77-87.

5. Oosterhuis HJ. Observations of the natural history of myasthenia gravis and the effect of thymectomy. Ann NY Acad Sci 1981; 377: 678-690.

6. Grob D, Brunner NG, Namba T. The natural course of myasthenia gravis and effect of therapeutic measures. Ann NY Acad Sci 1981; 377: 652-669.

7. Rowland LP, Hoefer PRA, Aranow HJR, Merritt HH. Fatalities in myasthenia gravis: a review of 39 cases with 26 autopsies Neurology 1956; 6: 307-326.

8. Buckingham JM, Howard FH, Bernatz PE, et al. The value of thymectomy in myasthenia gravis. Ann Surg 1976; 184: 453-458.

9. Simpson JA. Myasthenia gravis: a new hypothesis. Scot Med J 1960; 5: 419-436.

10. Millikan $\mathrm{CH}$, Eaton LM. Clinical evaluation of $\mathrm{ACTH}$ and cortisone in myasthenia gravis. Neurology 1951; 1: 145-152.

11. Kjaer M. Myasthenia gravis and myasthenic syndromes treated with prednisone. Acta Neurol Scand 1971; 47: 464-474.

12. Namba T, Brunner NG, Shapiro MS, Grob D. Corticotropin therapy in myasthenia gravis: effects, indications, and limitations. Neurology 1971;21: 1008-1018.

13. Grob D, Brunner NG, Namba T. The natural course of myasthenia gravis and effect of therapeutic measures. Ann NY Acad Sci 1981: 377: 652-669.

14. Grob D. Myasthenia gravis. Current status of pathogenesis, clinical manifestations, and management. J Chronic Dis 1958; 8: 536-566.

15. Linton DM, Philcox D. Disease a month (myasthenia gravis) 1990 ; 11: 599-637.

16. Osserman KE. Myasthenia gravis: New York Grune Stratton 1958.

17. Engel AG. Acquired autoimmune myasthenia gravis. In: Engel AG, Banker BQ, eds. Myology. New York, McGraw Hill, 1986; 1925-1954.

18. Drachman DB. Medical Progress - Myasthenia gravis II. N Engl J Med 1978; 298: 186-193.

19. Havard CWH, Scadding GK. Myasthenia gravis: pathogenesis and current concepts in management. Drugs 1983; 26: 174-184.

20. Simpson JA. Myasthenia gravis: a personal view of pathogenesis and mechanism, part I. Muscle Nerve 1978; 1: 45-56.

21. Simpson JA. Myasthenia gravis: a personal view of pathogenesis and mechanism, part II. Muscle Nerve 1978; 1: 151-156.

22. Patrick J, Lindstrom JM. Autoimmune response to acetylcholine receptor. Science $1973 ; 180 ; 871-872$.

23. Engel AG. In: Vinken PJ, Bruyen GW, eds. Handbook of Clinical Neurology, Vol. 41, Diseases of Muscle Part II. Amsterdam, North Holland, 1979; 95-145.

24. Simpson JA. Current concepts and history of the autoimmune nature of myasthenia gravis. In: Albuquerque EX, Eldefrawi AT, eds. Myasthenia gravis. London: Chapman and Hall 1983; 3-4l.
25. Oosterhuis HJGH. The ocular signs and symptoms of MG. Doc Ophthalmol 1982; 52: 363-378.

26. Chang CC, Chang ST, Huang MC. Effects of chronic treatment with various neuromuscular blocking agents on the number and distribution of acetylcholine receptors in the rat diaphragm. J Physiol 1975; 250: 161-173.

27. Engel AG, La mbert EH, Santa T. Study of long-term antiacetylcholinesterase therapy. Effects on neuromuscular transmission and on motor end-plate fine structure. Neurology 1973; 23: 1273-1281.

28. Aquilonius SM, Eckernas SA, Hartvig P, Lindstrom B, Osterman PO. Pharmacokinetics and oral bioavailability of pyridostigmine in man. Eur J Clin Pharmacol 1980; 18: 423-428.

29. Calvey TN, Chan K. Plasma pyridostigmine levels in patients with myasthenia gravis. Clin Pharmacol Ther 1977; 21: 1987-193.

30. White MC, deSilva P, Havard CVH. Plasma pyridostigmine levels in myasthenia gravis. Neurology 1981; 31: 145-150.

31. Aquilonius SM, Eckernas SA, Hartvig P, Lindstrom B, Osterman PO. Clinical pharmacology of neostigmine and pyridostigmine in patients with myasthenia gravis. J Neurol 1983; 46: 929-935.

32. Cohen MS, Younger D. Aspects of the natural history of myasthenia gravis: crisis and death. Ann NY Acad Sci 1981; 377: 670677.

33. Newsom-Davis J. Diseases of the neuromuscular junction. In: Asbury AK, McKhann GM, McDonald WI, eds. Diseases of the Nervous System. Clinical Neurobiology. WB Saunders Philadelphia 1986; 269-282

34. Dirr LY, Donofrio PD, Patton JF, Troost BT. A false-positive edrophonium test in a patient with a brainstem glioma. Neurology 1989; 39: 865-867.

35. Schwab RS, Perlo VP. Syndromes simulating myasthenia gravis. Ann NY Acad Sci 1966; 135: 350-366.

36. Osserman KE. Progress report on Mestinon bromide (pyridostigmine bromide). Am J Med 1955; 19: 737-739.

37. Osserman KE. Ocular myasthenia gravis. Invest Ophthalmol 1967; 6: 277-287.

38. Argov Z, Mastaglia FL. Drug therapy: disorders of neuromuscular transmission caused by drugs. N Engl J Med 1979; 301: 409-413.

39. Branceni D, Arnason BG. Thymic involution and recovery: immune responsiveness and immunoglobulins after neonatal prednisolone in rats. Immunology 1966; 10: 35-44.

40. Tindall RSA. Humoral immunity in myasthenia gravis: effects of steroids and thymectomy. Neurology 1980; 30: 554-557.

41. Howard FM Jr., Duane DD, Lambert EH, Daube DR. Alternateday prednisone; preliminary report of a double-blind controlled study. Ann NY Acad Sci 1976; 274: 596-607.

42. Pascuzzi RM, Coslett HB, Johns TR. Long term corticosteroid treatment of myasthenia gravis: report of 116 patients. Ann Neurol 1984; 15: 291-298.

43. Goldberg AL, Tischler M, DeMartino C, Griffin G. Hormonal regulation of protein degradation and synthesis in skeletal muscles Proc Fed Am Soc Exp Biol 1980; 39: 31-45.

44. Bergman RA, Afifi AK. Steroids myopathy. A study of the evolution of the muscle lesion in rabbits. Johns Hopkins Med J 1969; 124: 66-86

45. Brunner NG, Berger CL, Namba T, Grob D. Corticotropin and corticosteroids in generalized myasthenia gravis: comparative studies and role in management. Ann NY Acad Sci 1976; 274: 577-595.

46. Weir AI. The effects of corticosteroid treatment on neuromuscular transmission in rats with experimental auto-immune myasthenia gravis (EAMG). J Physiol 1982; 329: 43-44p.

47. Wolters MJ, Leeuwin RS. Effect of corticosteroids on the phrenic nerve-diaphragm of preparations treated with hemicholinium. A possible model for myasthenia gravis. Neurology 1976; 26: 574-578.

48. Leeuwin RS, Wolters MJ. Effects of corticosteroids on sciatic nerve-tibialis anterior muscles of rats treated with hemicholinium-3. An experimental approach to a possible mechanism of action of corticosteroids in myasthenia gravis. Neurology 1977 ; 27: $171-177$.

49. Engel WK, Festoff BW, Patten BM, Swerdlow ML, Newball HH, et al. Myasthenia gravis. Ann Intern Med 1974; 81: 225-246. 
50. Sghirlanzoni A, Peluchetti D, Mantegazza R, Fiacchino F, Cornelio F. Myathenia gravis: prolonged treatment with steroids. Neurology 1984; 34: 170-174.

51. Seybold ME, Drachman DB. Gradually increasing doses of prednisone in myasthenia gravis. Reducing the hazards of treatment. N Engl J Med 1974; 290: 81-84.

52. Seybold ME, Lindstrom JM. Patterns of acetylcholine receptor antibody fluctuation in myasthenia gravis. Ann NY Acad Sci 1981; 377: 292-306

53. Arsura EL, Brunner NG, Namba T, Grob D. High-dose intravenous methylprednisolone in myasthenia gravis. Arch Neurol $1985 ; 42: 1149-1153$.

54. Sakano T, Hamasaki T, Kinoshita Y, Kihara M, Ueda K. Treatment for refractory myasthenia gravis. Arch Dis Child 1989; 64: 1191-1193.

55. Smith SR, Terminelli C, Kipilman CT, Smith Y. Comparative effects of azathioprine, cyclophosphamide and frentizole on humoral immunity in mice. J Immunopharmacol 1979; 1: 455-481.

56. Schwartz RS. Specificity of immunosuppression by antimetabolites. Fed Proc 1966; 25: 165-176.

57. Chatenoud L, Chkoff N, Kreis H, Bach JF. Interest in and limitations of monoclonal anti-T-cell antibodies for the follow-up of renal transplant patients. Transplantation 1983; 36: 45-50.

58. Oger J, Antel J, Kuo HH, Arnason BGW. Influence of azathioprine (Imuran) on in vitro immune function in MS. Ann Neurol 1982; 11: 177-181.

59. Mertens HG, Hertel G, Reuther P, Ricker K. Effect of immunosuppressive drugs (azathioprine). Ann NY Acad Sci 1981; 377: 691-699.

60. Fronseca V, Harvard CW. Long-term treatment of myasthenia gravis with azathioprine. Postgrad Med J 1990; 66: 102-105.

61. Kissel JT, Levy RJ, Mendell JR. Griggs RC. Azathioprine toxicity in neuromuscular diseases. Neurology 1986; 36: 35-39.

62. Hohlfeld, Michels M, Heininger K, Besinger U, Tokya KV. Azathioprine toxicity during long-term immunosuppression of generalized myasthenia gravis. Neurology 1988; 38: 258-261.

63. Silman AJ, Petrie J, Hazelman B, Evans SJ. Lymphoproliferative cancer and other malignancy in patients with rheumatoid arthritis treated with azathioprine: a 20 year followup study. Ann Rheum Dis 1988; 47: 988-992.

64. Oger J, Deugnier Y, Hinault P, Sabouraud O. Experience of longterm immunosuppressive therapy in multiple sclerosis. In: Gonsette, ed. Immunosuppressive therapy in multiple sclerosis. Bruxelles, European Press, 1977; 100-113.

65. Scadding GK, Sweny P, Wilson SG, et al. Glomerulonephritis, thymoma and myasthenia gravis. Q J Med 1983; 206: 187-193.

66. Venkat Raman G, Sharman VL, Lee Ha. Azathioprine and allopurinol: a potentially dangerous combination. J Intern Med 1990; 228: 69-71.

67. Simpson JA, Thomaides T. Treatment of myasthenia gravis: an audit. Q J Med 1987; 64: 693-704.

68. Nagao T, White DJ, Calne RY. Kinetics of unresponsiveness induced by a short course of cyclosporin A. Transplantation 1982; 33: 31-35.

69. Drachman D, Adams R, McIntosh K, Pestronk A. Treatment of myasthenia gravis with cyclosporin A. Clin Immunol Immunopathol 1985; 34: 174-188.

70. Cohen DJ, Loertscher R, Rubin MF, Tilney NL, Carpenter CB, et al. Cyclosporin: a new immunosuppressive agent for organ transplantation. Ann Intern Med 1984; 101: 667-682.

71. Shevach EM. The effects of cyclosporin A on the immune system. Ann Rev Immunol 1985; 3: 397-423.

72. Borel JF. Animal experiments with cyclosporin. Triangle 1984; 23: 153-158.

73. Tindall RS, Rollins JA, Phillips JT, Greenlee RG, Wells L, et al. Preliminary results of a double-blind, randomized, placebo-controlled trial of cyclosporine in myasthenia gravis. $\mathrm{N}$ Engl J Med 1987; 316: 719-724.

74. Pestronk A, Drachman DB, Teoh R, Adams RN. Combined shortterm immunotherapy for experimental autoimmune myasthenia gravis. Ann Neurol 1983; 14: 235-241.

75. Pestronk A, Drachmann DB, Adams RN. Treatment of ongoing experimental MG with short term high dose cyclophosphamide. Muscle Nerve 1982; 5: 79-84.
76. Samra Y, Hertz M, Lindner A. Urinary bladder tumors following cyclophosphamide therapy: a report of two cases with review of the literature. Med Pediatr Oncol 1985; 13: 86-91.

77. Perez MC, Buot WL, Mercado-Danguilan C, Bagabaldo ZG, Renales LD. Stable remission in myasthenia gravis. Neurology $1981 ; 31: 32-37$

78. Hawkey CJ, Newsorm-Davis J, Vincent A. Plasma exchange and immunosuppressive drug treatment in myasthenia gravis: no evidence for synergy. J Neurol Neurosurg Psychiatry 1981; 44: 469-475.

79. Keesey J, Buffkin D, Kebo D, et al. Plasma exchange alone as therapy for myasthenia gravis. Ann NY Acad Sci 1981; 377: 729-743.

80. Newsom-Davis J. Wilson SG, Vincent A, et al. Long-term effects of repeated plasma exchange in MG. Lancet 1979; 1: 464-468.

81. Olarte MR, Schoenfeldt RS, Penn AS, et al. Effect of plasmapheresis in MG. 1978-1980. Ann NY Acad Sci 1981; 377: 725728 .

82. Gajdos P, Simon N, de Rohan, Chabot P, Raphael JC, et al. Longterm effects of plasma exchange in myasthenia. Results of a randomized study. Presse Medicale. Paris 1985; 12: 939-942.

83. Seybold ME, Tsoukas C, Lindstrom J, Fong S, Vaughan J. Leukoplasmapheresis for myasthenia gravis. Acetylcholine receptor antibody production. Arch Neurol 1982; 39: 433-435.

84. Verma P, Aziz T, Oger J. In vitro non-specific immune function in myasthenia gravis 1991 (Abstract) Ann Neurol 1991; 30(2): 305.

85. D'Empaire G, Hoaglin DC, Perlo VP, et al. Effects of prethymectomy plasma exchange on postoperative repiratory function in myasthenia gravis. J Thorac Cardiovasc Surg 1985; 89: 592-596.

86. Howard JF Jr., Sanders DB, Johns TR. The role of plasma exchange therapy in myasthenia gravis. Presented at the Haemonetics Research Institute Advanced Component Seminar. June 1978.

87. Dau PC, Lindstrom JM, Cassel CK, Denys EH, Shev EE, et al. Plasmapheresis and immunosuppressive drug therapy in myasthenia gravis. N Engl J Med 1977; 297: 1134-1140.

88. Donat JFG, Donat JR, Lennon VA. Exchange transfusion in neonatal myasthenia gravis. Neurology 1981; 31:911-912.

89. Drachman DB. Treatment of myasthenia gravis. In: Annual Courses of American Academy of Neurology 1983.

90. Rodnitzky RL, Bosch EP. Chronic long-interval plasma exchange in myasthenia gravis. Arch Neurol 1984; 41: 715-717.

91. Somnier FE, Langvad E. Plasma exchange with selective immunoadsorption of anti-acetylcholine receptor antibodies. J Neuroimmunol 1989; 22: 123-127.

92. Weigart G. The thymus in myasthenia gravis. Neurol Zantrabl 1901; 20: 597-602.

93. Schumacher J. Roth J. Thymektomie bei einem Fall von Morbus Basedowii mit Myasthenie. Mitt Grenzebieten. Med Chir 1913; 25: 746-765.

94. Blalock A, Mason MF, Morgan HJ, Riven SS. Myasthenia gravis and tumors of the thymic region. Report of a case in which the tumor was removed. Ann Surg 1939; 110: 544-559.

95. Blalock A. Thymectomy in the treatment of myasthenia gravis. Report of twenty cases. J Thorac Surg 1944; 13: 316-339.

96. Bofill M, Janossy G, Willcox N, Chilosi M, Trejdosiewicz LK, et al. Microenvironments in the normal thymus and the thymus in myasthenia gravis. Am J Pathol 1985; 119: 462-473.

97. Castleman B. The pathology of the thymus gland in myasthenia gravis. Ann NY Acad Sci 1966; 135: 496-505.

98. Lisak RP, Levinson AI, Zweiman B, Kornstein M. In vitro synthesis of IgG and antibodies to AChR by peripheral and thymic lymphocytes. Ann NY Acad Sci 1987; 505: 39-49.

99. Schluep M, Wilcox N, Vincent A, Dhoot GK, Newsom-Davis J. Acetylcholine receptors in human thymic myoid cells in situ: an immunohistological study. Ann Neurol 1987; 22: 212-222.

100. Blalock A, Harvey AM, Ford FR, Lilienthal JL. Treatment of myasthenia gravis by removal of the thymus gland. J Am Med Assoc 1941; 117: 1529-1533.

101. Simpson JA. An evaluation of thymectomy in myasthenia gravis. Brain 1958; 81: 112-145.

102. Perlo VP, Arnason B, Poskanzer D, et al. The role of thymectomy in the treatment of myasthenia gravis. Ann NY Acad Sci 1971; 183: $308-315$. 
103. Janssen RS, Kaye AD, Lisak RP, et al. Radiologic evaluation of the mediastunum in myasthenia gravis. Neurology 1983; 33: 534-539.

104. Simpson JA. Myasthenia gravis and myasthenic syndromes. In: Walton JN, ed. Disorders of Voluntary Muscles. Edinburgh London/New York Livingstone 1981; 585-624.

105. Vincent A, Newsom-Davis J, Newton P, Beck N. Acetylcholine receptor antibody and clinical response to thymectomy in myasthenia gravis. Neurology 1983; 33: 1276-1282.

106. Kagotani K, Monden Y, Nakahara K, Fujii Y, Seike Y, et al. Antiacetylcholine receptor antibody titre with extended thymectomy in myasthenia gravis. J Thorac Cardiovasc Surg 1985; 90:7-12.

107. Verma P, Oger J. Seronegative generalized myasthenia gravis: low frequency of thymic pathology. Neurology 1992; 42: 586-589.

108. Lisak RP, Levinson AI, Zweiman B, Kornstein M. Antibodies to AchR and tetanus toxoid: in vitro synthesis by thymic lymphocytes. J Immunol 1986; 137: 1221-1225.

109. Kaufman R, Oger J. Antibody production by blood lymphocytes in myasthenia gravis: reduction in disease of long duration. Neurology 1988; 38: 818-821.

110. Sommer N, Willcox N, Harcourt GC, Newsom-Davis J. Myasthenic thymus and thymoma are selectively enriched in acetylcholine receptor-reactive T cells. Ann Neurol 1990; 28: 312-319.

111. Donaldson DH, Ansher M, Horan S, Rutherford RB, Ringel SP. The relationship of age to outcome in myasthenia gravis. Neurology 1990; 40: 786-790.

112. Jansen PH, Renier WO, De Vaan G, et al. Effect of thymectomy on myasthenia gravis and autoimmune thrombocytopenic purpura in a 13-year-old girl. Eur J Pediatr 1987; 146: 587-589.

113. Ferguson TB, Clifford DB, Montogomery EB, et al. Thymectomy in multiple sclerosis. J Thorac Cardiovasc Surg 1983; 85: 88-93.

114. Szobor A. Benefit of thymectomy in immune diseases other than myasthenia. Lancet 1984; 1:277-278.

115. Kuroda $Y$, Oda K, Heshige R, et al. Exacerbation of myasthenia gravis after removal of a thymoma having a membrane phenotype of suppressor T-cells. Ann Neurol 1984; 15: 400-402.

116. Denayer MA, Rao KR, Wirz D, McNally D. Hepatic metastatic thymoma and myasthenia gravis twenty-two years after the apparent cure of an invasive thymoma. A case report and review of literature. J Neurol Sci 1986; 76: 23-30.

117. Huang MH, King KL, Hsu WH, Huang BS, Hsu HK, et al. The outcome of thymectomy in nonthymomatous myasthenia gravis. Surg Gynecol Obstet 1988; 166: 436-440.

118. Kimura J, Van Allen MW. Post-thymectomy myasthenia gravis. Neurology 1967; 17: 413-420.

119. Mulder DG, Hermann C Jr, Keesey J, et al. Thymectomy for MG. Am J Surg 1983; 146; 61-66.

120. Olanow CW, Lane RJ, Roses AD. Relationship between the acetylcholine receptor antibody titer and the clinical status in MG. Ann NY Acad Sci 1981; 377: 856-857.

121. Penn AS, Jaretzki A 3d, Wolff M, et al. Thymic abnormalities: antigen or antibody? Response to thymectomy in myasthenia gravis. Ann NY Acad Sci 1981; 377: 786-804.

122. Maggi G, Casadio C, Cavallo A, Cianci R, Molinatti M, et al. Thymectomy in myasthenia gravis. Results of 662 cases operated upon in 15 years. Eur J Cardio-thorac Surg 1989; 3: 504-509.

123. Papatestas AE, Genkins G, Horowitz SH, et al. Thymectomy in MG: pathologic, clinical and electrophysiological correlations. Ann NY Acad Sci 1976; 274: 555-573.

124. Papatestas AE, Genkins G, Kornfeld P. Comparison of the results of trans-cervical and trans-sternal thymectomy in myasthenia gravis. Ann NY Acad Sci 1981; 377: 766-778.

125. Austin EH, Olanow CW, Wechsler AS. Thymoma following transcervical thymectomy for myasthenia gravis. Ann Thorac Surg 1983; 35: 548-550.

126. Cooper JD, Al-Jilaihawa AN, Pearson FG, Humphrey JG, Humphrey HE. An improved technique to facilitate transcervical thymectomy for myasthenia gravis. Ann Thorac Surg 1988; 45: 242-247.

127. Olanow CW, Lane RJM, Roses AD. Thymectomy in late-onset myasthenia gravis. Arch Neurol 1982; 39: 82-83.

128. Lanska DJ. Indications for thymectomy in myasthenia gravis. Neurology 1990; 40: 1828-1829.
129. Morris J. Thymectomy: a recommended procedure for myasthenia gravis. J Neurosurg Nurs 1981; 13: 226-233.

130. Spence PA, Morin JE., Katz M. Role of plasmapheresis in preparing myasthenic patients for thymectomy: initial results. Can J Surg 1984; 27: 202-305.

131. Mann JD, Johns TR, Campa JF. Long-term administration of corticosteroids in myasthenia gravis. Neurology 1976; 26: 729-740.

132. Dias-Tosta E, Morato-Fernandes RN. Myasthenia gravis: treatment with thymectomy, corticoids and plasmapheresis. Arquivos De Neuro-Psiquiatria. 1989; 47: 39-50.

133. Fraser K, Simpson JA, Crawford J. The place of surgery in the treatment of myasthenia gravis. Br J Surg 1978; 65: 301-304.

134. Hofmann WE, Reuther P, Schalke B, Mertens HG. Splenectomy in myasthenia gravis: a therapeutic concept? J Neurol 1985; 232: 215-218.

135. Coker DD, Morris DM, Coleman JJ, Schimpff SC, Wiernick PH, et al. Infection among 210 patients with surgically staged Hodgkin's disease. Am J Med 1983; 75: 97-109.

136. Engel WK, Lichter AS, Dalakas MC. Splenic and total-body irradiation treatment of myasthenia gravis. Ann NY Acad Sci 1981; 377: 744-754.

137. Arsura EL, Bick A, Brunner NG, Namba T, Grob D. High dose intravenous immunoglobulin in the management of myasthenia gravis. Arch Intern Med 1986; 146: 1365-1368.

138. Pahwa RN. New and controversial uses of intravenous gammaglobulin. Ped Infect Dis J 1988; 7(Suppl): S34-36.

139. Maruyama Y, Takeshita S, Sekine I, Yoshioka S. High-dose immunoglobulin for juvenile myasthenia gravis. Acta Paediatrica Japonica - Overseas Edition. 1989; 31: 544-548.

140. Zweiman B. Theoretical mechanisms by which immunoglobulin therapy might benefit myasthenia gravis. Clin Immunol Immunopathol 1989; 53: S83-91.

141. Antel JP, Medof ME, Oger J, Kuo HH, Amason BGW. Generation of suppressor cells by aggregated human globulin. Clin Exp Immunol 1981; 43(2): 351-356.

142. Patrik J, Boulter J, Goldman D, et al. Molecular biology of nicotinic acetylcholine receptors. Ann NY Acad Sci 1987; 505: 194 207.

143. Noda M, Furutani $Y$, Takahashi $H$, et al. Cloning and sequence analysis of calf cDNA and human genomic DNA encoding alpha-subunit precursor of muscle acetylcholine receptor. Nature $1983 ; 305: 818-823$.

144. Fuchs S, Bartfeld D, Mochly-Rosen D, et al. Acetylcholine receptor: molecular dissection and monoclonal antibodies in the study of experimental myasthenia, Ann NY Acad Sci 1981; 377: 110-124.

145. Lennon VA, Lambert EH. Monoclonal auto antibodies to acetylcholine receptors: evidence for a dominant idiotype and requirement of complement for pathogenicity. Ann NY Acad Sci 1981; 377: 77-96.

146. Sterz RK, Biro G, Rajki K, Filipp G, Peper K. Experimental autoimmune myasthenia gravis: can pretreatment with 125-I labeled receptor prevent functional damage at the neuromuscular junction? J Immunol 1985; 134: 841-846.

147. Feher J, Filipp G, Koscar L, Mohari K, Toncsev H, et al. Inhibition of autoimmune hepatitis with hot labelled liver specific antigen. Clin Exp Immunol 1984; 55: 360-368.

148. Thorpe PE, Mason DW, Brown AN, Simmonds SO, Ross WC, et al. Selective killing of malignant cells in a leukemic rat bone marrow using an antibody-ricin conjugate. Nature 1982; 297: 594-596.

149. Vallera DA, Ash RC, Zanjani ED, Kersey JH, LeBien T, et al. AntiT-cell reagents for human bone marrow transplantation: ricin linked to three monoclonal antibodies. Science 1983; 222: 512-514.

150. Quinones RR, Youle RJ, Kersey JH, Zanjani EE, Azemove SM, et al. Anti-T-cell monoclonal antibodies conjugated to ricin as potential reagents for human GVHD prophylaxis: effect on the generation of cytotoxic $T$ cells in both peripheral blood and bone marrow. J Immunol 1984; 132: 678-683.

151. Gilliland DG, Steplewski Z, Collier RJ, Mitchell KF, Chang TH, et al. Antibody-directed cytotoxic agents: use of monoclonal antibody to direct the actions of a toxic ricin A chains to 
colorectal carcinoma cells. Proc Natl Acad Sci U.S.A. 1980; 77 4539-4543.

152. Vitetta ES, Krolick KA, Miyama-Anaba M, Cushley W, Uhr J. Immunotoxins: a new approach to cancer therapy. Science 1983; 219: 644-655.

153. Gilliland DG, Steplewski Z, Collier RJ, Mitchell KF, Chang TH, et al. Antibody-directed cytototoxic agents: use of monoclonal antibody to direct the actions of a toxin A - chains to colorectal carcinoma cells. Proc Natl Acad Sci U.S.A. 1980; 77: 45394543.

154. Hashimoto N, Takatsu K, Masuho Y, Kishida K, Hara T, et al. Selective elimination of a B cell subset having acceptor site(s) for $\mathrm{T}$ cell-replacing factor (TRF) with biotinylated antibody to the acceptor site(s) and avidin-ricin A - chain conjugate. J Immunol 1984; 132: 129-135.

155. Killen JA, Lindstrom JM. Specific killing of lymphocytes that cause experimental autoimmune myasthenia gravis by ricintoxin-acetylcholine receptor conjugates. J Immunol 1984; 133: 2549-2553.

156. Olsberg CA, Mikiten TM, Krolick KA. Selective in vitro inhibition of an antibody response to purifed acetylcholine receptor by using antigen-ricin A chain immunotoxin. J Immunol 1985; 135: 3062-3067.

157. Thorpe PE, Brown AN, Ross WC, et al. Cytotoxicity acquired by conjugation of anti-Thy 1.1 monoclonal antibody and the ribosome-inactivating protein, gelonin. Eur J Biochem 1981; 116: 447-454.

158. Brust S, Fillip G, Hofmann U, et al. Antigen-gelonin conjugates. Preparation and application in experimental myasthenia gravis. Biological chemistry Hoppe-Seyler 1987; 368: 991-999.

159. Glennie MJ, McBride HM, Stirpe F, Thorpe PE, Worth AT, et al. Emergence of immunoglobulin variants following treatment of a B cell leukemia with an immunotoxin composed of anti-idiotypic antibody and saporin. J Exp Med 1987; 166: 43-62.

160. Hurwitz E, Maron R, Bernstein A, Wilchek M, Sela M, et al. The effects in vivo of chemotherapeutic drug-antibody conjugates in two murine experimental tumor systems. Int J Cancer 1978; 29: 747-755.

161. Levy R, Hurwitz E, Maron R, Arnon R, Sela M. The specific cytotoxic effects of daunomycin conjugated to antitumor antibodies. Cancer Res 1975; 35: 1182-1186.

162. Belles-Isles M, Page M. In vitro activity of daunomycin-antialpha-foetprotein conjugate on mouse hepatoma cells. $\mathrm{Br} \mathrm{J}$ Cancer 1980; 41: 841-842.

163. Diener E, Diner UE, Sinha A, Xie S, Vergridis R. Specific immunosuppression by immunotoxin containing daunomycin. Science 1986; $231: 148-150$

164. Donald DH, Ansher M, Horan S, Rutherford RB, Ringel SP. The relationship of age to outcome in myasthenia gravis. Neurology 1990; 40: 786-790.

165. Szobor A, Fornet B. Myasthenia gravis: ${ }^{75}$ seleno-methionine scanning of thymus gland. Acta Med Hung 1986; 43: 243-248.
166. Jaretzki A 3d, Penn AS, Younger DS, Wolff M, Olarte MR, et al. "Maximal" thymectomy for myasthenia gravis. Results. J Thorac Cardiovas Surg 1988; 95: 747-757.

167. Osserman KE, Tsairis P, Weiner LB. Myasthenia gravis and thyroid disease: clinical and immunological correlation. J Mt Sinai Hosp 1967; 34: 469-483.

168. Engel AG. Thyroid function and myasthenia gravis. Arch Neurol 1961; 4: 663-674.

169. Witoonpanich R, Vejjajiva A, Limpisvastis S. Regional curare test in the study of neuromuscular transmission in hyperthyroidism. J Med Assoc of Thailand 1989; 72 (Suppl 1): 187-191.

170. Argov Z, Mastaglia FL. Drug therapy: disorders of neuromuscular transmission caused by drugs. N Engl J Med 1979; 301: 409413.

171. Bennett DA, Bleck TP. Recognizing impending respiratory failure from neuromuscular causes. J Crit Illness 1988; 3: 46-60.

172. Perlo VP. Treatment of the critical ill patient with myasthenia. In: Ropper AH, Kennedy SK, Zervis NT, eds. Neurology and Neurosurgical Intensive Care. Baltimore University Park Press, 1983; 157-161.

173. Gracey DR, Divertie MB, Howard FM, et al. Postoperative respiratory care after transsternal thymectomy in myasthenia gravis. Chest 1984; 86: 67-71.

174. Gracey DR, Diuvertie MB, Howard FM. Mechanical ventilation for respiratory failure in myasthenia gravis: two year experience with 22 patients. Mayo Clin Proc 1983; 58: 597-602.

175. Namba T, Brown SD, Grob D. Neonatal MG: 2 cases with a review of the literature. Pediatrics 1970; 45: 488-504.

176. Oosterhuis HJGH Studies in Myasthenia Gravis Part I a clinical study of 180 patients. J Neurol Sci 1964; 1: 512-546.

177. Engel AG, Lambert EH, Mulder, et al. Recently recognized congenital myasthenic syndromes. Ann NY Acad Sci 1982; 377: 614-639.

178. Lindstrom J. An assay for antibodies to human acetylcholine receptor in serum for patients with myasthenia gravis. Clin Immunol Immunopathol 1977; 7: 36-43.

179. Mier A, Havard CVH. Diaphragmatic myasthenia in mother and child. Postgrad Med J 1985; 61: 725-727.

180. Mossman S, Vincent A, Newsom-Davis J. Myasthenia gravis without acetylcholine receptor antibody: a distinct disease entity. Lancet 1986; 1: 116-119.

181. Walker M. Treatment of myasthenia gravis with physostigmine. Lancet 1934; 1: 1200-1201.

182. Kornfeld P, Horowitz SH, Genkins G, Papatestas A. Myasthenia gravis unmasked by antiarrhythmic agents. Mt Sinai J Med 1976; 43: 10-14

183. White MC, de Silva $\mathrm{P}$, Havard $\mathrm{CVH}$. Plasma pyridostigmine levels in myasthenia gravis. Neurology 1981; 31: 145-150.

184. Wojciechowski APJ, Hanning CD, Pohl OZ. Postoperative apnoea and latent myasthenia gravis. Value of acetylcholine receptor antibody estimation in the differential diagnosis. Anesthesia 1985; 40: 882-884 